Check for updates

Cite this: RSC Adv., 2020, 10, 1066

Received 17th August 2019

Accepted 29th October 2019

DOI: $10.1039 / \mathrm{c} 9 \mathrm{ra06447h}$

rsc.li/rsc-advances

\section{A review of fibrous materials for soft body armour applications}

\author{
Unsanhame Mawkhlieng, (DD a Abhijit Majumdar ${ }^{\star a}$ and Animesh Laha ${ }^{\text {ab }}$
}

A critical review on the factors affecting the impact resistance behaviour of soft body armour is presented here. The effect of several material and structural parameters of fibrous assemblies used in soft armour is dealt with in depth. The standards of performance evaluation of soft body armour and modes of energy absorption are elucidated. The paper also reviews different approaches resorted to by the researchers to enhance the ballistic or stab resistance performance of these soft body armour materials. These approaches include surface treatments and modifications of the base material to increase yarn to yarn friction as well as implementation of 3D woven fabrics to enhance structural integrity. Among these, the effect of shear thickening fluid (STF) is discussed extensively. The review concludes with the future directions of research in the area of soft body armour.

\section{Introduction}

Body armour is a protective gear which is used to protect the human body against attacks of various kinds of sharp objects or projectiles. Body armour is broadly classified into two categories, namely hard body armour and soft body armour. ${ }^{1}$ Hard body armour, with protection of levels III and IV according to the National Institute of Justice (NIJ) standard, ${ }^{2}$ is reinforced with metal, ceramic $\left(\mathrm{B}_{4} \mathrm{C}\right)$ or fibre based composite plates within layers of fabric. They are used by military personnel in high risk operations for protection against high speed bullets or

${ }^{a}$ Department of Textile and Fibre Engineering, Indian Institute of Technology Delhi, India 110016. E-mail: majumdar@textile.iitd.ac.in

${ }^{b}$ Business Development Division, Reliance Industries, Mumbai, India projectiles fired from weapons like AK-47s. They are heavy and rigid and thus, they restrict wearer's movement. In contrast, soft body armour is made of multiple layers of high-performance fabrics, making it lighter in weight and more flexible. Police, security personnel, riot officers, etc., use this type of armour against low velocity projectile attacks from handguns, pistols, shotguns, etc., for lower levels (NIJ levels II-A, II, and III-A) of ballistic protection. ${ }^{2,3}$ In general, 20-40 layers of woven or unidirectional fabrics, made from high performance fibres, are stitched together to prepare the soft body armour panels. Therefore, they are still bulky and heavy enough to restrict the agility of the wearer. Consequently, these limitations present several challenges when it comes to reduction of armour weight, effective improvement in terms of handling multiple ballistic shots and back face signature or BFS reduction. ${ }^{4}$

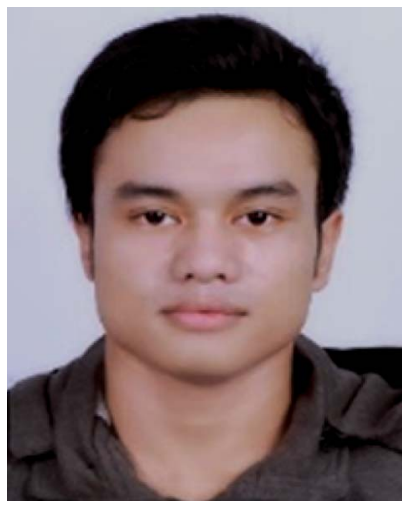

Unsanhame Mawkhlieng is a doctoral candidate in Textile and Fibre Engineering at Indian Institute of Technology Delhi, India. He is working in the field of protective textiles, particularly, in 3D weaving for ballistic applications. He has a Bachelor of Engineering in Textile Engineering from Amravati University and a Master of Technology in Textile Engineering from IIT Delhi. He also has one and a half year industrial experience in spinning. He has published a research paper in Composites Part B: Engineering, and also authored a Textile Progress monograph on 'Soft Body Armour'.

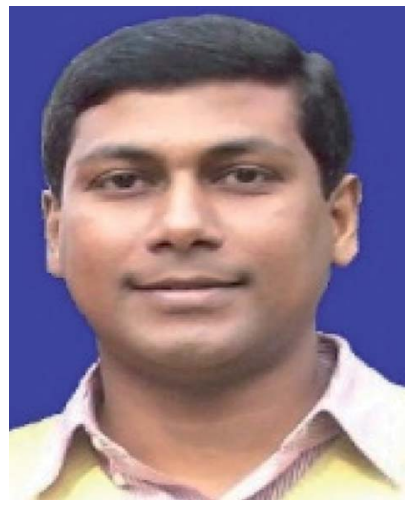

Abhijit Majumdar is an Institute Chair Professor in Textile and Fibre Engineering at Indian Institute of Technology Delhi, India. He has published 100 research papers in international refereed journals and guided nine PhD students. He has been involved in high value projects with Defence Research and Development Organization, India. He is a recipient of Outstanding Young Faculty Fellowship (2009-2014) of IIT Delhi, Teaching Excellence Award (2015) of IIT Delhi and Gandhian Young Technological Innovation Award (2017). 
The history of body armour materials is as old as human civilization. Their evolution with time has been briefly reviewed by Yadav et al. ${ }^{5}$ First generation soft body armour was prepared from silk by the medieval Japanese. ${ }^{6}$ Used during the World War I, this armour provided good protection against very low velocity projectiles (up to $\approx 120 \mathrm{~m} \mathrm{~s}^{-1}$ ) but not so, against projectiles having higher velocity $\left(\approx 180 \mathrm{~m} \mathrm{~s}^{-1}\right)$. Second generation soft body armour, prepared from nylon flak,, ${ }^{7,8}$ was introduced during the World War II. Although it proved to be a very good barrier against munition fragments, it, however, failed against most of the pistol and rifle threats. Besides, it was bulky and heavy. The next generation of soft body armour development started with the invention of high-performance $p$-aramid fibre (Kevlar®) by DuPont, back in the 1960s. Presently, highperformance fibre based soft body armour are used as routine wear by police officers and security personnel to achieve protection against low speed ballistic threats including hand grenades, spike attacks and ice picks. High performance fibres used for such purposes include $p$-aramid (Kevlar®, Technora ${ }^{\circledR}$, Twaron ${ }^{\circledR}$ etc.), ultra-high molecular weight polyethylene or UHMWPE (Dyneema® ${ }^{\circledR}$, Spectra ${ }^{\circledR}$ etc.), poly $p$-phenylene benzobisoxazole or PBO (Zylon ${ }^{\circledR}$ ), polyhydroquinone-diimidazopyridine or PIPD fibres (M5), etc. ${ }^{9-11}$ The essential properties of the above fibres are low density $\left(0.97\right.$ to $\left.1.6 \mathrm{~g} \mathrm{~cm}^{-3}\right)$, high tenacity $(2.5-5.8 \mathrm{GPa})$ and high modulus (70-270 GPa). ${ }^{12}$ Several attempts have been made by fibre manufacturers and material researchers to develop new materials and improved structures so that the efficacy of soft body armour can be enhanced. Researchers have also explored the possibility of using multiaxial warp knitted fabrics and 3D woven fabrics in soft body armour. ${ }^{\mathbf{1 3 , 1 4}}$ In the last two decades, the idea of using shear thickening fluid (STF) to improve the energy absorption capability of soft body armour has interested many researchers. The pioneer work in this area was done by Lee et al. ${ }^{15-17}$ in the early 2000s. They demonstrated that the impact resistance of woven fabrics can be enhanced significantly with STF treatment. Some reviews on body armour systems, ${ }^{1}$ ballistic protective clothing, ${ }^{12}$

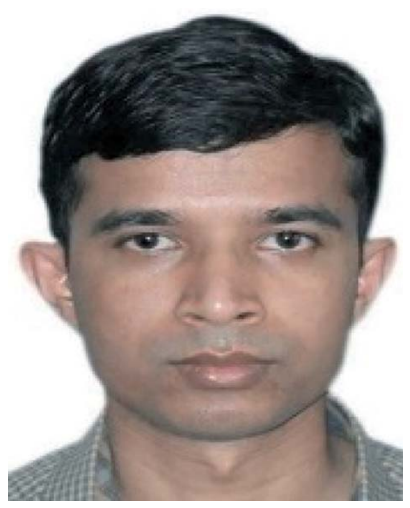

Animesh Laha is an assistant manager of Reliance Industries Limited, India in Advanced Materials Division. He acquired M.Tech. degree in Chemical Processing of Textiles from Govt. College of Engineering and Textile Technology, Serampore and PhD in Textile and Fibre Engineering from Indian Institute of Technology Delhi, India. He has published 8 research papers in international refereed journals and 16 papers national and international conferences. His research areas include protective fibrous materials and new material development. He is a recipient of Gandhian Young Technological Innovation Award (2017) and Hari Om Ashram Prerit Dr Amulya K. N. Reddy Award (2017). evolution of soft body armour ${ }^{18}$ and body armour for stab and spike protection ${ }^{\mathbf{1 9}}$ have been presented by researchers to provide a proper understanding of the field. This review presents the material (fibre) and structural (yarn and fabric) parameters influencing impact energy absorption in Section 2. Standards for evaluation of soft body armour is shown in Section 3. Mechanism of impact energy absorption is presented in Section 4. A detailed review of approaches to enhance the performance of soft body armour materials is highlighted in Section 5. Section 6 deals with some of the future trends in soft armour development.

\section{Parameters influencing impact energy absorption}

Arora and Ghosh ${ }^{\mathbf{1 8}}$ collectively summarised the various parameters which contribute to the impact performance of soft armour panel. They classified these parameters into four categories - material parameters, structural parameters, projectile parameters and testing parameters. Material parameters include fibre density, fibre tenacity, fibre modulus and yarn to yarn friction. Structural parameters include yarn twist, weave, thread density, number of layers, etc. Projectile related parameters such as mass, shape and velocity, and testing related parameters such as shot location, number of shots, angle at which the bullet strikes the target and boundary conditions can affect the ballistic performance greatly. However, in-depth discussion of projectile and testing parameters is out of the scope of this review. Material and structure related parameters are discussed in the following section.

\subsection{Material properties}

2.1.1 Density, tenacity and modulus. Fibre properties are of paramount importance for soft body armour. As mentioned earlier, fibres to be used for armour applications must have low density, high tensile modulus, high tenacity and low elongation at break. Fig. 1 pictorially presents the superiority of high performance fibres in terms of modulus and tenacity. ${ }^{\mathbf{1}}$ Different high-performance fibres exhibit varying properties from each other, making them suitable for specific applications. Similarly, different variants of the same fibre might be useful for different applications. For example, $p$-aramid fibre, Kevlar 49 (elastic modulus, $113 \mathrm{GPa}$; tensile strength, $2.96 \mathrm{GPa}$ ) is recommended for use in ropes, cables and composites for marine, aerospace and sport goods applications whereas Kevlar 129, which has relatively lower modulus (96 GPa) and higher tensile strength (3.39 GPa) and lower elongation (3.5\%), is recommended for impact and soft armour applications. ${ }^{20}$ A comparative analysis of properties high-performance fibres can be obtained from published literature ${ }^{\mathbf{1 8 , 2 1}}$ Similarly, aramid fibres Twaron® (tensile strength, 3.1 GPa and modulus, $121 \mathrm{GPa}$ ) and Technora ${ }^{\circledR}$ (tensile strength, $3 \mathrm{GPa}$ and modulus, $70 \mathrm{GPa}$ ) are also suitable for armour applications. ${ }^{22}$ Taparan ${ }^{\circledR}$, yet another $p$ aramid fibre has properties similar to Kevlar 129. UHMWPE fibres have a significantly lower density $\left(0.97 \mathrm{~g} \mathrm{~cm}^{-3}\right)$ than those of aramid fibres $\left(1.44 \mathrm{~g} \mathrm{~cm}^{-3}\right)$ which makes the former a better 
alternative where armour mass is a critical design parameter. Moreover, UHMWPE (Dyneema) is claimed to lose only about $5 \%$ of its strength when exposed to UV rays over a period of two days, while aramid fibre (Kevlar) loses up to $25 \%$ of its strength when subjected to similar conditions. ${ }^{23}$ Another fibre with ballistic potential is Zylon, which shows much better tensile properties (tenacity, $5.8 \mathrm{GPa}$ ) than $p$-aramid and UHMWPE fibres. However, following the failure of Zylon vests to protect a couple of US police officers from gunshot injury in 2003, the prospect of Zylon as a ballistic material was then questioned. It was later found that Zylon fibre is vulnerable to hydrolytic and photolytic degradation at an accelerated rate during usage and storage. Therefore, the use of Zylon fibre as soft body armour materials is no longer recommended by the U.S. army. ${ }^{24}$ M5 fibre, another fibre with promising ballistic properties, has an average modulus (310 $\mathrm{GPa}$ ) which is much higher than that of most of the carbon fibres commercially available. Its tenacity is appreciably higher than that of aramid fibres, though at par with that of Zylon (up to $5.8 \mathrm{GPa}) .{ }^{11}$ Although Fig. 1 portrays carbon fibres as a superior alternative due to its high modulus, however, the strain to break is very low that the fibre becomes brittle and not suitable for impact applications. ${ }^{12}$

The ballistic performance of a woven fabric may be evaluated from its single yarn component. ${ }^{25}$ When a single fibre is hit by a projectile transversely, two waves simultaneously propagateone, longitudinally and the other, transversely as shown in Fig. 2. While the longitudinal waves travel at the speed of sound, the transverse waves travel at a much slower speed. This is because, as the impact progresses, the yarn deflects itself in the direction of impact. The velocity of the longitudinal strain wave generated in a fibre due to impact can be determined by using eqn (1).

$$
C=\sqrt{\frac{E}{\rho}}
$$

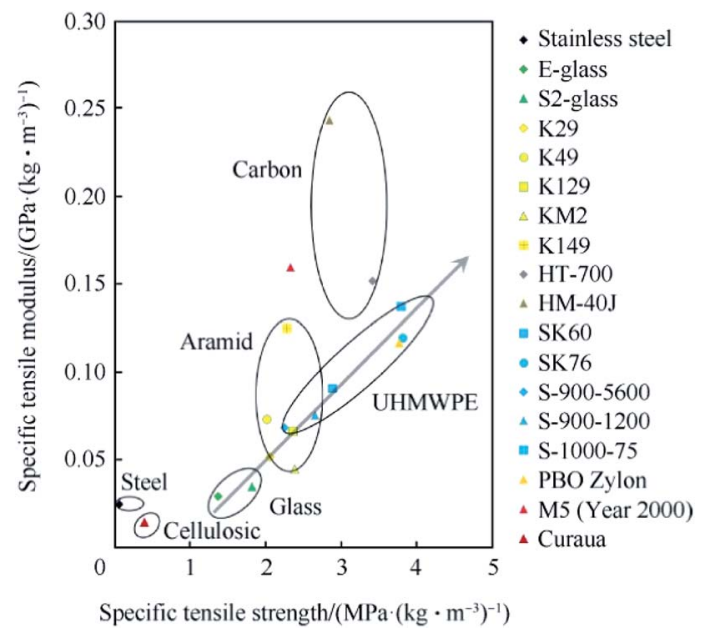

Fig. 1 Relationship between specific tensile modulus and specific tensile strength of high-performance fibres ${ }^{1}$ (this figure has been reproduced from ref. 1 with permission from Elsevier). where, $C$ is the speed of longitudinal wave, $E$ is the initial modulus and $\rho$ is the density of fibre.

Transverse stress wave speed $(u)$, on the other hand, is dependent on the tensile strain $(\varepsilon)$ of the filament or yarn during impact and is related to the longitudinal stress wave velocity. Mathematically, it is given by eqn (2).

$$
u=C \sqrt{\frac{\varepsilon}{1+\varepsilon}}
$$

Cunniff, ${ }^{25}$ deduced a dimensionless fibre property $U$ (defined as the product of specific fibre toughness and its strain wave velocity) as given in eqn (3).

$$
U=\frac{\sigma \varepsilon}{2 \rho} \sqrt{\frac{E}{\rho}}
$$

where, $\sigma$ is the ultimate tensile strength of the fibre, $\varepsilon$ is the ultimate tensile strain of fibre.

This equation shows that for better impact resistance, tensile strength and modulus of the fibre should be high whereas fibre density should be low. Besides, the fibres intended for body armour applications should also have properties like low moisture retention, high resistance to heat, high limiting oxygen index, etc.

2.1.2 Friction. Friction between the yarns and between the yarn and the projectile at the time of impact plays an important role in determining the impact performance of fabrics. ${ }^{26}$ It is well grounded that increased inter-yarn friction improves the pull-out force, and hence the energy absorption. ${ }^{27-36}$ Bazhenov $^{28}$ concluded that the dissipation of energy increases with the increase in pull-out zone dimensions. The latter, in turn, depends upon the increased involvement of more and more secondary yarns which is a direct positive consequence of yarn to yarn friction. The findings of Duan et al. also support this argument. ${ }^{29}$ The authors used FEA to have a better understanding of the role of friction and the numerical investigation showed that friction prevents the yarns from laterally sliding past each other, thus enabling more yarns to break and energy absorption to increase. It was also reported that when yarn breaks, energy absorption is enhanced. The role of friction is not only to enhance energy through frictional sliding, but also through increased yarn kinetic energy as well as through improved yarn strain energy.

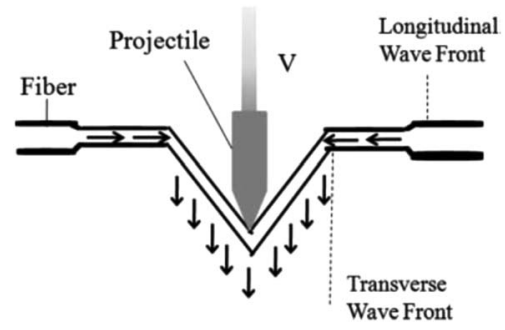

Fig. 2 Pictorial representation of projectile impacting a single yarn ${ }^{6}$ (this figure has been reproduced from ref. 6 with permission from Elsevier). 
According to Zeng et al., ${ }^{30}$ coefficient of friction can be divided into three distinct ranges, namely, low $(\mu=0.0-0.06)$, moderate $(\mu=0.06-0.2)$ and high $(\mu=0.2-1) .{ }^{30}$ Very low coefficient of friction results in poor integrity of the structure and thus, the projectile resisting power is reduced. It was observed that the increase of energy absorption is highly 'sensitive' to this given low range of friction, i.e., even with slight increase in friction coefficient, the energy absorption increased markedly. Moderate coefficient of friction $(\mu=0.2)$ caused maximum energy absorption, while at coefficient of friction higher than 0.2 , the energy absorption tended to fall, as shown in Fig. 3, due to localised stress concentration. Thus, the role and amount of friction can be seen to be very influential in energy absorption during ballistic impact.

With this understanding in mind, many researchers worked towards improving the friction by using resins, polymeric coatings and additives such as nanostructures for more energy absorption. ${ }^{31}$ As a matter of fact, the use of STF itself, as believed by many researchers ${ }^{32,33}$ helps in improved performance majorly through friction enhancement. Nanorods of metal oxides are also used to intensify friction between yarns. The development and use of such nanorods is described in greater detail in Section 5.7. The work by Gawandi et $a .^{34}$ on the influence of polymeric coating on tow pull-out response of Kevlar showed enhanced friction, and hence, pull-out force. Here, it is important to note that relative humidity can greatly influence the coefficient of friction of hydrophilic fibres. For hydrophobic fibres, water can act as a lubricant, reducing the yarn pull-out force. Similarly, softening treatments drastically reduce the yarn to yarn friction. ${ }^{35,36}$

\subsection{Structural parameters}

2.2.1 Yarn twist. Most high performance as-received multifilament yarns are twistless, making their handling a little difficult due to tendency of defilamentation. Therefore, twist may be applied for ease of operation and better performance. It is well established that twist insertion to a fibre strand increases its strength initially. However, after a certain level of twist, obliquity effect takes precedence and strength reduces. ${ }^{37} \mathrm{~A}$ study by Rao and Farris ${ }^{38}$ showed that an optimum twist angle of about $7^{\circ}$ provides maximum tensile strength; an angle

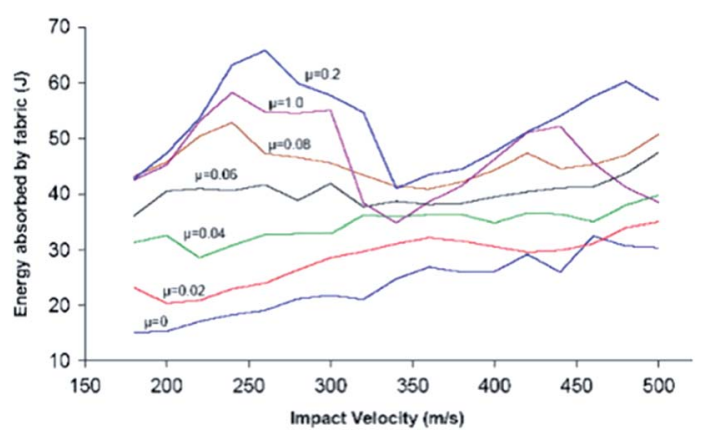

Fig. 3 Effect of yarn to yarn friction on energy absorption during impact $^{30}$ (this figure has been reproduced from ref. 30 with permission from John Wiley and Sons). beyond this reduces the tensile strength and increases the breaking elongation.

2.2.2 Fabric structure. Different fabric structures, such as unidirectional (UD), 2D woven, 3D woven, multiaxial, warp knitted and nonwoven (as cushion layers), used as soft body armour materials, ${ }^{\mathbf{1 2 , 1 4 , 3 9 - 4 4}}$ also affect the ballistic performance of the panels. In the context of $2 \mathrm{D}$ fabrics, balanced weaves like plain and basket are found to be more suitable as soft body armour materials due to uniform mechanical properties in the two principal directions. ${ }^{\mathbf{4 0 4}}$ Crimpless UD fabrics in which filaments are laid in two perpendicular directions and bonded by some resins outperform woven fabrics having similar areal density as the wave propagates faster through the former. Bandaru et $a .^{\mathbf{4 6 , 4 7}}$ studied the effect of different fabric architectures on low velocity impact behaviour and found that $3 \mathrm{D}$ architecture outperformed 2D plain woven structure in terms of peak force and energy absorption, both in neat and composite structures, due to enhanced structural integrity. Additionally, the tensile properties were also reported to be higher for all 3D angle interlock samples in terms of strength and failure strain. ${ }^{\mathbf{4 6}}$

For ballistic applications, fabrics must have an optimum level of thread density. Very tight fabrics will cause the yarns to deteriorate during weaving, while too loose a construction will not be able to stop the bullet from piercing through; a phenomenon commonly called as 'wedge through'. In fact, it has been reported that fabric cover should have a value ranging from 0.6 to 0.95 for effective ballistic performance. ${ }^{48,49}$ Bajaj and Sriram $^{12}$ reviewed that tight structures woven from yarns consisting of large number of filaments with finer denier are beneficial for efficient ballistic protection, particularly for finer projectiles. Laha et $a .^{45}$ reported the influence of fabric construction for ballistic protection and found that jammed fabrics inhibited movement of yarns during impact, consequently, preventing the critical shear rate, needed for STF, from being achieved.

2.2.3 Crimp. Yarn crimp is known to slow down the speed wave propagation in ballistic impact. ${ }^{50}$ When a projectile strikes a fabric having high crimp, the fabric shows less resistance against the projectile as yarn stretching occurs without much difficulty. ${ }^{51}$ This is because the crimped yarns in the fabric take more time to absorb energy, as they initially straighten and then stretch. Higher the crimp, more is the deflection in transverse direction and larger is the back face signature or blunt trauma. ${ }^{52}$ It is interesting to note that the experimental results of Laha et $a l .{ }^{45}$ showed that plain woven outperformed the other weaves in terms of impact resistance performance. This might seem contradicting, given that a plain-woven fabric has higher crimp in comparison to twills and satins. This, perhaps, suggests that there must exist an optimum balance between number of contact points and crimp level. Chitrangad ${ }^{48}$ suggested the use of hybrid fabric in which weft yarns have higher failure strain. Thus, during impact, weft yarns will take more time to break, resulting in both warp and weft yarns to break about the same time. Logically speaking, a more feasible approach is to develop fabrics with same amount of crimp in both directions. However, contrary to this, Sadegh and Cavallaro ${ }^{54}$ reported that crimp imbalance in woven fabrics has a substantial effect on the 
energy absorption, stating that there exists an optimum level of crimp imbalance that would give maximum level of energy absorption for a particular threat. They observed and argued that for fully perforating impacts, a crimp-balanced structure reflected higher back wave energy from the site of impact, negatively affecting the ballistic performance.

\subsection{Number of fabric layers and stitching}

A single layer of high-performance fabric is insufficient to ensure protection against high velocity impact. ${ }^{18}$ Therefore, a soft body armour against high velocity impact is generally comprised of several layers of high-performance fabrics sewn or stitched together. ${ }^{39}$ Expectedly, as the number of layers increases, the trauma depth and diameter decrease. The supportive findings of Karahan et al. ${ }^{53}$ also showed that with the increase in the number of layers (from 20 to 32), trauma depth (by $35.4 \%$ ) and trauma diameter (by 12.7\%) decreased (Fig. 4).

The requirement of multiple layers necessitates adhesion or stitching of layers for considerable thickness. This extra adhesion or stitching process increases the stiffness of the fabric assembly which reduces the mobility of wearer. Although it is known that stitching partly damages the yarns ${ }^{55}$ and generates local stress-concentrated points on the fabric, however, stitching also plays the important role of binding the layers together, thus preventing delamination from occurring. An experiment conducted by Ahmad et al. ${ }^{56}$ on unstitched and stitched neat and natural rubber coated fabrics showed that, in general, stitched fabrics performed better than the unstitched ones. Stitch patterns like one inch field diamond, two inches field diamond, diagonal and perimeter stitching were used, and except for the one inch diamond stitched fabrics, unstitched samples showed lower ballistic limit. On the other hand, two inches field pattern gave the highest ballistic limit.

\subsection{Orientation of fabric layers}

As discussed in the previous section, multiple layers of highperformance fabric are required to get enough protection against high velocity impact. Stacking of multiple layers to make a single panel can be done in different ways. As shown in

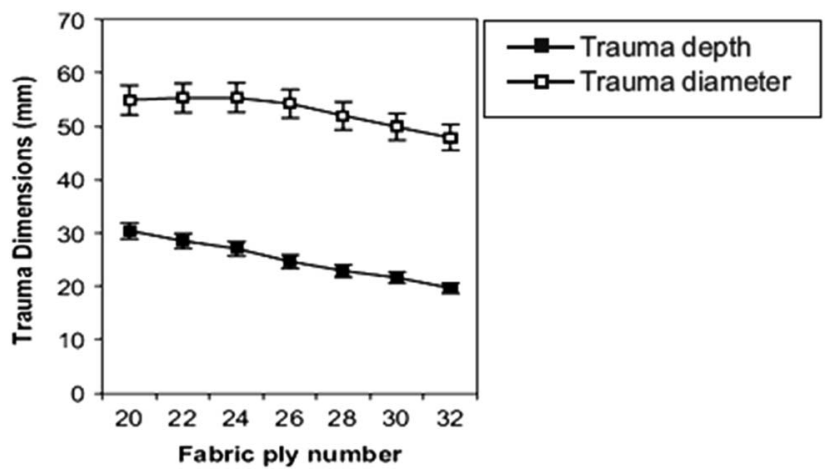

Fig. 4 Effect of number of fabric layers on the trauma depth and diameter $^{53}$ (this figure has been reproduced from ref. 53 with permission from Elsevier).
Fig. 5, Chen et al. and Wang et al. ${ }^{57,58}$ carried out detailed study on the effect of orientation of fabric laying on impact energy absorption. They found that impact energy absorption was always lower when all the fabric layers were aligned in $0^{\circ}$. The highest impact energy absorption was obtained for two, three, four and eight layered fabric panels using the angle of orientations [0/45], [0/30/60], [0/22.5/45/67.5] and [(0/22.5/45/67.5) $\times$ 2 ], respectively. Overall 11.4 to $18.5 \%$ increase in the impact energy absorption was obtained by using different orientations of fabrics in different layers. This is because as the different fabric layers are oriented along different axes, the assembly approaches isotropy. Post impact, the pyramid formed has a quadrilateral base because of the two principal axes along which the diagonals of the base align. Hence, if there are more than two sets of perpendicular axes, as in the case of a multilayered fabric with angle ply orientation, the base may tend to be circular, so that the pyramid approximately becomes a cone and hence, the energy absorption increases.

\section{Standards for body armour evaluation}

There are different standards for evaluating the performance of body armour. Standards form National Institute of Justice (NIJ), USA: NIJ 0101.06, NATO STANAG 4569, Home Office Scientific Development Branch (UK), European Ballistic Standards (EU), GOST Ballistic Standards (Russia), German SCHUTZKLASSE standard, International Ballistic Standards, are some of the available options. However, NIJ 0101.06 (ref. 2) is the most widely used standard for body armour evaluation. According to this standard, body armour is categorised into five classes based on the level of protection they provide - IIA, II, IIIA, III and IV. Type IIA, II and IIIA provide lower level of protection corresponding to different projectile type and mass and different projectile velocities of $355 \mathrm{~m} \mathrm{~s}^{-1} \pm 9 \mathrm{~m} \mathrm{~s}^{-1}$ to $448 \pm 9 \mathrm{~m} \mathrm{~s}^{-1}$. A new unworn armour is subjected to higher velocity as compared to a conditioned armour. Type III and IV, however, provide protection against projectiles having higher velocity of $847 \mathrm{~m}$ $\mathrm{s}^{-1} \pm 9.1 \mathrm{~m} \mathrm{~s}^{-1}$ and $878 \mathrm{~m} \mathrm{~s}^{-1} \pm 9.1 \mathrm{~m} \mathrm{~s}^{-1}$, respectively. Unlike type IIA, II and IIIA, both new and conditioned type III and IV

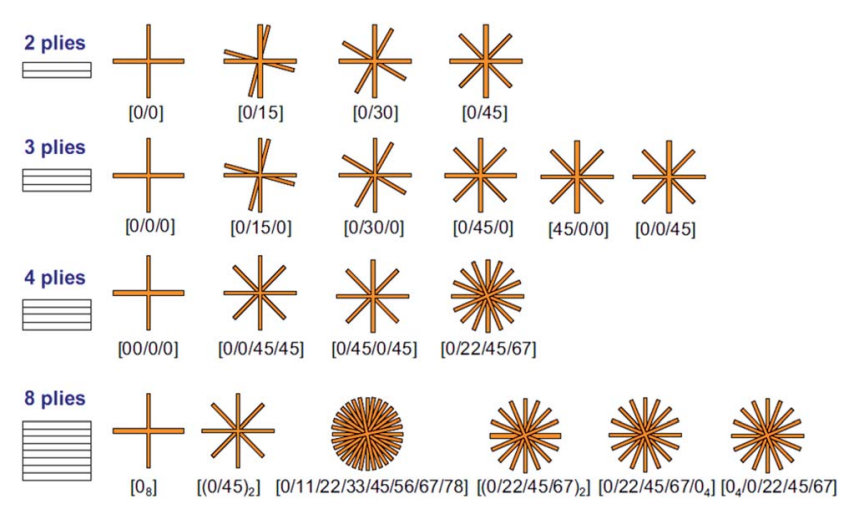

Fig. 5 Ply orientations of ballistic panels ${ }^{57}$ (this figure has been reproduced from ref. 57 with permission from Elsevier). 
armour are subjected to the same projectile velocity. Additionally, the formers are subjected to two test rounds, whereas the latter, to one. The number of shots per panel in all cases is standardised to 6 . NIJ has also come up with a revised version NIJ 0101.07 which has been propounded for scrutiny and comments. ${ }^{3}$ Recently, the Bureau of Indian Standards has published a standard for ballistic evaluation (IS17051:2018), categorised in six levels (Level 1 to Level 6) based on the bullet weight, type and velocity. ${ }^{60}$ The permissible BFS as per the requirement of Indian army is $25 \mathrm{~mm} .^{61}$

During ballistic evaluation, energy absorption by the test panel can be determined by using pre-impact and post-impact residual velocities of the projectile which are measured with the help of two chronographs positioned before and after the panel being tested (Fig. 6). This method is useful in case of complete perforation of the test panel by the projectile. The energy absorbed by the test panel is calculated by using eqn (4).

$$
E=\frac{1}{2} m\left(v_{1}^{2}-v_{2}^{2}\right)
$$

where, $E$ is the energy absorbed, $v_{1}$ is the pre-impact velocity and $v_{2}$ is the residual velocity of projectile.

$V_{0}$ and $V_{50}$ are also used as parameters to evaluate the performance of body armour. $V_{0}$ and $V_{50}$ signify the bullet velocities at which the probability of penetration is 0 and 0.5 , respectively. After firing a series of bullets, the bullet with the minimum velocity which perforates the armour and the bullet with the maximum velocity which is stopped by the armour are taken for consideration. The velocity for 0.5 probability of perforation is then determined normally by considering at least two cases of complete penetration and two cases of stoppage (Fig. 7).

Another important aspect of soft armour evaluation is blunt trauma or back face signature (BFS) which is usually measured for a non-perforation type impact. ${ }^{62}$ When a bullet is stopped by the armour, a trauma or crater is formed on the backing material with a certain diameter, depth and volume which represent the transmission of energy to the back side of armour. Therefore, after ballistic testing, the depth, diameter and volume of trauma is measured as shown in the Fig. $8 .^{53}$ According to NIJ standard, the maximum permissible BFS is 44 $\mathrm{mm}$. For measuring the trauma, the test panel is backed or supported with an easily deformable substance. Clay backing

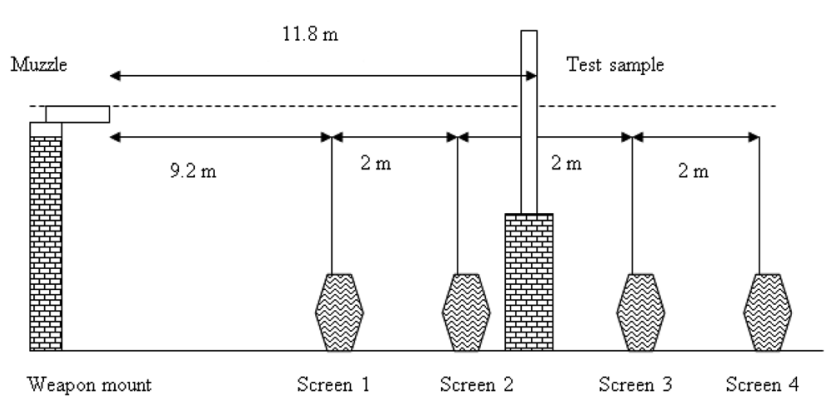

Fig. 6 Impact velocity determination using chronograph ${ }^{59}$ (this figure has been reproduced from ref. 59 with permission from Elsevier).
(Roma Plastilina) readily supports post-test linear and volumetric measurements and therefore, it is popularly used for blunt trauma evaluation. Other resilient materials, such as ballistic gelatin do not retain the deformation after impact. Therefore, in such cases, the trauma should be characterised with photographic equipment, force gauges, etc. $^{64}$

\section{Energy absorption mechanisms of soft body armour}

When a high-performance fabric is hit by a projectile, energy is absorbed through various mechanisms, depending on both material and projectile parameters. ${ }^{\mathbf{1 2 , 5 9 , 6 5 - 6 7}}$ During impact, the bullet can either completely or partially pierce through or can be entirely halted by the target. The fabric target absorbs energy through the following mechanisms: ${ }^{.65,66,68}$

- Yarn decrimping

- Fibre and yarn extension

- Yarn pull-out

- Fibre and yarn rupture

The relationships between these mechanisms and the ultimate ballistic performance of high-performance fabrics is yet to be understood fully. When a bullet strikes a fabric, crimp removal, yarn extension, pyramid formation by primary and secondary yarns, fibrillation and fibre breakage happens in sequence absorbing significant amount of energy. Fibre fusing is also observed in case of thermoplastic materials. It is generally accepted that yarn pull-out (Fig. 9) is a consequence of low yarn to yarn friction ${ }^{\mathbf{1 7 , 6 9 , 7 0}}$ and hence, yarn pull-out test is a good step towards understanding the role of friction during impact.

\subsection{Yarn pull-out}

The earliest studies on yarn pull-out was reported by Sebastian et al. on plain woven cotton fabrics. ${ }^{71,72}$ In a typical yarn pull-out test, single or multiple yarns are pulled out from a highperformance woven fabric to measure of yarn to yarn friction. Fig. 10 shows two distinct regions in a yarn pull-out force $v s$. displacement graph, namely static friction region or crimp

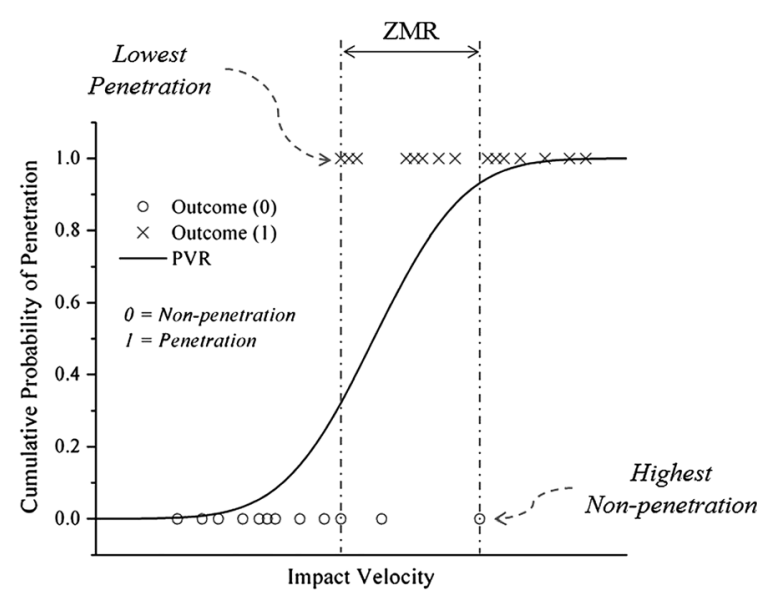

Fig. 7 Determination of $V_{50}$ (ref. 63) (this figure has been reproduced from ref. 63 with permission from Elsevier). 

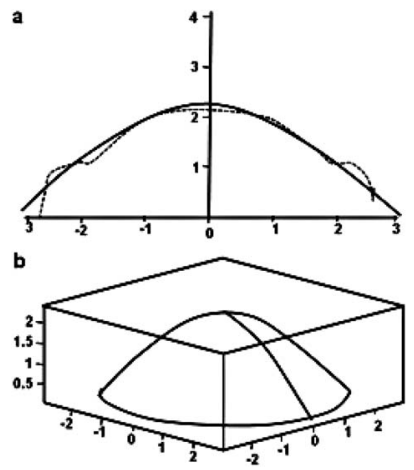

Fig. 8 Evaluation of back face deformation. (a) Comparison of measured and fitted curves, (b) view of 3-D model of trauma obtained by a curve fitted using spline curve fitting method ${ }^{53}$ (this figure has been reproduced from ref. 53 with permission from Elsevier).

removal region and dynamic friction region or stick-slip region. In Region I, with the application of pull-out force, the yarn starts to straighten via the irreversible process of crimp removal. The peak force is reached when yarn crimp becomes zero. Thereafter, dynamic friction comes into play in the 'yarn translation' region which witnesses stick-slip effect. ${ }^{28,73}$ 'Stick' occurs when the yarn being pulled out is held by the transverse yarns, while 'slip' takes place when the yarn slides over the transverse yarns $^{35,70,74-77}$ as depicted in Region II and III of Fig. 10. The plateau region in Region II is where the pulled yarn begins to slide relative to the fabric and the Region III is where the yarn starts to disengage from the fabric.

There are various factors which influence yarn pull-out results. The physical state, linear density, surface texture and surface treatment of the yarn play great roles during yarn pullout. Other influencing factors are sample dimensions and thread density. Martinez et al. ${ }^{73}$ carried out friction and wear experiment on three variants of Kevlar fabrics and found that the static coefficient of friction (defined as the ratio of frictional force to contact force) was the highest in the tightest fabric sample, i.e., the sample with the highest thread density. Similarly, the pull-out force, defined in terms of frictional force per yarn crossover and frictional force per unit length of the yarn drawn out, were found to be highest for the same densest sample, clearly indicating that pull-out force increases as the thread density increases.
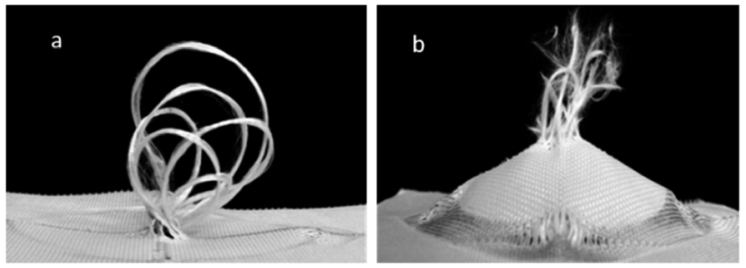

Fig. 9 Fabric failure mechanisms during impact (a) yarn pull-out and (b) fibre and yarn rupture ${ }^{68}$ (this figure has been reproduced from ref. 68 with permission from Elsevier).

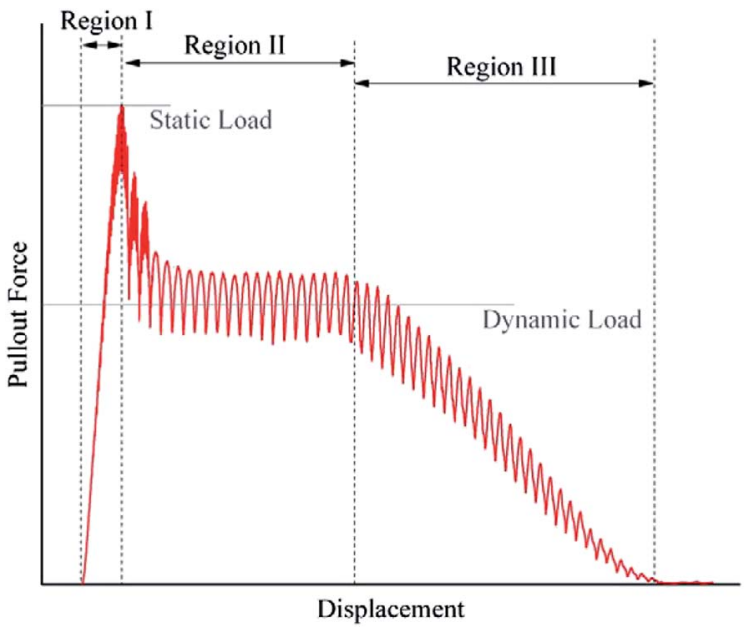

Fig. 10 Pull-out response of a single yarn from a woven fabric ${ }^{36}$ (this figure has been reproduced from ref. 36 with permission from Elsevier).

On a similar but different note, Bilisik et al. ${ }^{77}$ conducted single and multiple yarn pull-out experiments on Twaron fabrics and found supporting results in which the fabric sample with the highest thread density showed the highest pull-out force for single yarn pull-out.

However, for multiple yarn pull-out, the same translation was not observed because with the denser fabric, excess fibre breakage was observed. Bazhenov ${ }^{28}$ and Bilisik et al. ${ }^{77}$ showed that pull-out force also increased with increasing specimen length and in general, the same trend was also observed with increasing sample width. Weave, out-of-plane deformation, shear and transverse tension also influence yarn pull-out force. A two-dimensional finite element model developed by Dong and $\mathrm{Sun}^{74}$ also showed that thread density, yarn waviness, yarn friction and modulus are factors affecting yarn pull-out force. The parametric study gave rise to the simple eqn (5) that can be used for a fair estimation of pull-out force:

$$
F=C \times \mathrm{TD}^{4} \times D^{2} \times M \times W \times F_{\mathrm{c}}
$$

where, $F$ is the normalised pull-out force (N per denier), $C=$ 0.573 is a constant, TD is the yarns per inch, $D$ is diameter of fibre in meter, $M$ is of fibre modulus in Pascal, $W$ is the yarn waviness in meter and $F_{\mathrm{c}}$ is coefficient of yarn friction.

Pull-out force decreases with the increase in pull-out speed, the reduction being higher for static pull-out loads than it is for dynamic pull-out loads. ${ }^{36}$ Pull-out force and crimp extension are higher in case of multiple yarn pull-out tests.

\section{Approaches to improve the impact resistance}

Researchers have explored different approaches to improve the impact resistance of woven fabrics as soft body armour material. Among these approaches, use of natural latex, use of shear thickening fluid (STF), fabric surface modification by 
developing nanorods of metal oxides and use of 3D woven fabrics are the few important ones. The idea of using STF or even surface modification is to enhance structural integrity through friction. On the other hand, the purpose of employing $3 \mathrm{D}$ woven structures is to enhance through-thickness mechanical properties. Because $2 \mathrm{D}$ woven structures are devoid of components in the $Z$-direction, hence, the load bearing capacity along the thickness can be improved by making use of 3D woven structures. The aspect of 3D woven fabrics and their role in ballistic applications will be discussed later in more detail.

\subsection{Use of latex/natural rubber coating}

Ahmad et al. ${ }^{78}$ coated the Twaron fabrics with high modulus pre-vulcanised natural rubber by simple dipping technique. The ballistic performance of the all-neat samples was inferior to that of the composite system of neat and coated fabrics. Additionally, the number of layers penetrated by the projectile was less in the case of coated samples for the same projectile velocity. A related work done by Roy et al. ${ }^{79}$ also showed similar findings, besides showing that the energy absorption increased with increasing add-on percentage. Hassim et al. ${ }^{80}$ carried out puncture resistance test of unidirectional fabric after single dipping (SD), double dipping (DD) and triple dipping (TD) of samples with oily and dry probe and observed that the puncture resistance increased with increasing number of dipping, i.e., with increasing amount of natural latex.

\subsection{Use of shear thickening fluids (STF)}

The application of shear thickening fluid (STF) for ballistic protection has attracted several research groups in recent years. Gürgen $e t ~ a l .{ }^{32}$ has thoroughly reviewed the applications of STF for protective applications and therefore, the present work will only briefly describe this aspect. STF has been explored and used for low velocity impact applications ${ }^{81,82}$ stab and spike protection $^{83-92}$ as well as for high velocity ballistic impact applications. ${ }^{17,93,94}$ Shear thickening fluid (STF) is a non-Newtonian fluid having two phases, namely dispersed phase and dispersion medium. Initially with the application of shear, STF shows shear thinning behaviour. However, after achieving a particular shear rate, called critical shear rate, viscosity increases abruptly and the liquid suspension attains an almost solid like state. ${ }^{15,21,94-99}$ Fig. 11 shows the phenomenon of shear thickening. The dispersed phase of STF consists of nano-scale or sub-micron particles of silica, calcium carbonate or polymethylmethacrylate (PMMA), etc., while the dispersion medium of STF can be water, silicon oils, polyethylene glycol (PEG), polypropylene glycol (PPG) or 1-butyl-3-methylimidazolium tetrafluoroborate. ${ }^{100-105}$ In most of the reported literature, researchers have used colloidal silica nanoparticles or fumed silica as dispersed phase and PEG as dispersion medium. ${ }^{17,106-111}$ The choice of PEG is probably due to its nontoxicity, ease of handle and thermal stability. Sonochemical technique, high speed homogenization, use of magnetic stirrer, ultrasound sonication (using water bath or probe), etc., have been used by researchers for proper dispersion of particles in STF by breaking intermolecular interactions of nano particles. ${ }^{108,112-114}$ The phenomenon of shear thickening, fabrication method, rheological response and applications of STF have also been reviewed by Ding et al. ${ }^{115}$

Hasanzadeh et al. ${ }^{110}$ and Srivastava et $a .^{21}$ also reviewed the significance of STF and its influence on ballistic, stab, impact and puncture resistance of high performance textile materials.

\subsection{Theories of shear thickening}

A few theories, namely, order-disorder transition (ODT), hydrocluster theory, jamming and dilation theory have been proposed by researchers to explain the shear thickening behaviour.

5.3.1 Order-disorder theory. When a stabilised dense colloidal suspension is subjected to shearing forces at relatively lower shear rate, the inherent repulsive interaction among the particles in the solution prevents them from coming together, keeping them in an ordered, layered kind of stable arrangement. However, as the shear rate keeps on increasing, beyond a certain critical point, the shear forces pushing the particles together become strong enough to overcome the repulsive particle to particle interaction. This gives rise to a disordered arrangement due to particles being forced out of their equilibrium state. ${ }^{100-102,117}$ Gurnon et al. ${ }^{118}$ reported that the competition and balance between hydrodynamic (dissipative) and thermodynamic (conservative) forces control the non-Newtonian shear rheology of a colloidal suspension under steady and flow conditions. However, some studies later showed that the occurrence of order-disorder transition is not mandatory for shear thickening to occur. ${ }^{119,120}$

5.3.2 Hydrocluster theory. First introduced by Brady and Bossis, hydrocluster theory states that for suspensions interacting through hydrodynamic forces, the rise in viscosity upon increasing shear rate can be attributed to cluster formation. ${ }^{121}$

At low shear rate, Brownian motion is prevalent and hence the particles are in equilibrium as shown in Fig. 12(a). With the application of very low shear rate, particles organise themselves in various layers resulting in shear thinning as shown in Fig. 12(b). On further increase in shear rate, formation of selforganised microstructures takes place which are bonded by hydrodynamic forces. These microstructures, known as

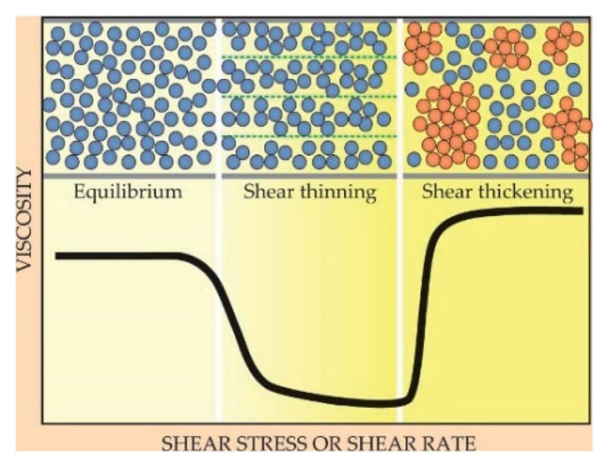

Fig. 11 Schematic representation of shear thickening behaviour ${ }^{96}$ (this figure has been reproduced from ref. 96 with permission from American Institute of Physics). 
hydroclusters, are a small, irregularly shaped clustered mass composed of particles which are momentarily compressed together. The particles within the momentarily formed hydroclusters itself are so minutely spaced that the assembly as a whole is incompressible, rendering the solid like behaviour that governs the shear thickening phenomenon. As a result shear thickening is obtained as shown in Fig. 12(c). ${ }^{\mathbf{1 0 4 , 1 2 3 - 1 2 7}}$ Cheng et al. ${ }^{128}$ was able to visualise the formation of hydroclusters during shear thickening in concentrated colloidal suspensions with the help of fast confocal microscopy. This theory is able to predict the onset of shear thickening for a wide range of continuous and discontinuous shear thickening fluids, although simulations are not able to produce the same level of high viscosity observed in experiments.

5.3.3 Dilation theory. Earlier, dilatancy was used to explain the shear thickening, although generally, dilatancy refers to the expansion of a system due to change in packing arrangement. ${ }^{129}$ Metzner and Whitlock ${ }^{\mathbf{1 3 0}}$ differentiated the two dilatancies (one, in the rheological and the other, in the volumetric sense) and found that the two occur independent of each other.

Thereafter, explanation of shear thickening as a mechanism leans towards the hydrocluster theory. However, more recently, dilatancy in the volumetric sense, as a possible explanation to shear thickening was proposed by Brown and Jaeger. ${ }^{131}$ When volumetric dilation of a granular shear flow is confined by boundary conditions, internal stresses develop in the system. Equal and opposite forces are then transmitted to the particles which then come in contact with each other, contributing to the frictional contact forces. This, in accordance to the latest theory of contact rheology, contributes to the abrupt rise in viscosity of the system under high shear rate. ${ }^{\mathbf{1 3 1 , 1 3 2}}$

5.3.4 Contact rheology. In recent years, a new model is laid down by Seto et al. ${ }^{\mathbf{1 3 3}}$ to overcome the limitation of the hydrocluster theory by taking into account the solid friction among the contacting particles similar to granular suspensions, in addition to the lubrication forces that govern the hydrocluster theory. The role of frictional forces has been supported by experiments and it is suggested that it is the major driving force when the gap between particles fall below a certain limiting value. As shown in Fig. 12(d), Qin et al. ${ }^{116}$ hypothesised that in case of high solid content, shear thickening is dictated by jamming of particles akin to a logjam

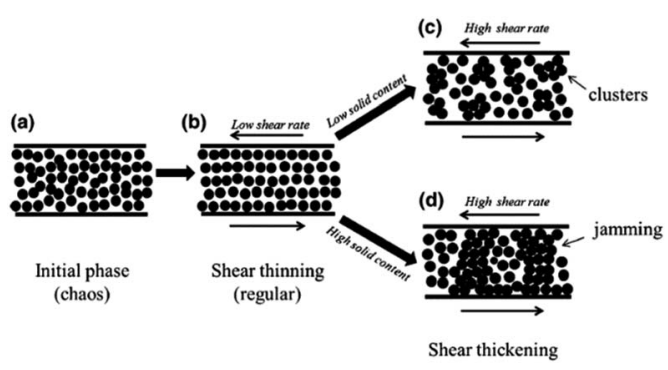

Fig. 12 Schematic illustrations of microstructure of particles under shear force: (a) randomly dispersed, (b) shear thinning, (c) cluster formation begins, (d) jamming ${ }^{116}$ (this figure has been reproduced from ref. 116 with permission from Springer Nature). while at lower solid content, shear thickening is governed by hydrocluster formation. However, it was found later by Lin et al. ${ }^{134}$ that contact forces also dictate continuous shear thickening (CST) as well where the solid content can be as low as $49 \%$. Therefore, the contact model is able to predict the behaviour of both continuous and discontinuous shear thickening.

\subsection{Parameters influencing shear thickening behaviour}

It has been observed that the behaviour of shear thickening fluid primarily depends on particle related parameters like solid content, particle aspect ratio, particle shape, particle size and its distribution, and so on. Other parameters like temperature and $\mathrm{pH}$ and carrier fluid properties are also influential.

5.4.1 Solid content. Solid content of particles in concentrated colloidal suspensions is the most important parameter affecting shear thickening behaviour. Shear thickening is observed only when the solid content exceeds a certain minimum level. Barnes ${ }^{\mathbf{1 2 5}}$ reported that a phase volume of $50 \%$ is a good approximation around which shear thickening commences, although it is not necessarily true as reported by many prior researchers. This value has been taken for granted due to the fact that the dependence of critical shear rate on phase volume is least at around $50 \%$. Critical shear rate decreases non-linearly and peak viscosity increases with the increase in volume fraction (Fig. 13). Boersma et al. ${ }^{117}$ numerically predicted the critical shear rate for different dispersions and found that for almost all dispersions (consisting of spherical dispersed particles with stabilizing layer thickness lesser than the particle diameter), critical shear rate depends on the volume fraction, particularly, when the fraction is closer to the maximum value.

5.4.2 Aspect ratio, shape, size and size distribution of particle. Along with the solid content, particle aspect ratio (length : diameter) also critically affects the shear thickening behaviour of concentrated colloidal suspensions. It has been observed that with increase in particle aspect ratio, critical shear rate reduces, and viscosity increases probably because of the manner in which these particles interact. Besides, the minimum solid content required to achieve shear thickening also decreases with increasing particle aspect ratio. Wetzel et al. ${ }^{135}$ used spherical silica particles and $\mathrm{CaCO}_{3}$ particles of different aspect ratios ranging from $2: 1$ to $7: 1$ and found that as the aspect ratio increases, requirement of solid volume fraction to reach the critical shear rate decreases.

Particle shape has considerable influence on flow properties of concentrated colloidal suspensions. Although it is well established that particle shape is an important influential parameter as far as shear thickening is concerned, it is however, unclear as to what contributes to the effect. Whether it is the shape on its own that plays a role, or the combined effect of shape and other parameters such as size, volume fraction and so on, is still not fully understood. However, in general, it is observed that anisotropic particles more readily give shear thickening, and hence, suspensions with rod shaped or needle shaped particles have greater propensity for shear thickening behaviour than particles with plate, grains or sphere shapes. ${ }^{110,125,135}$ 


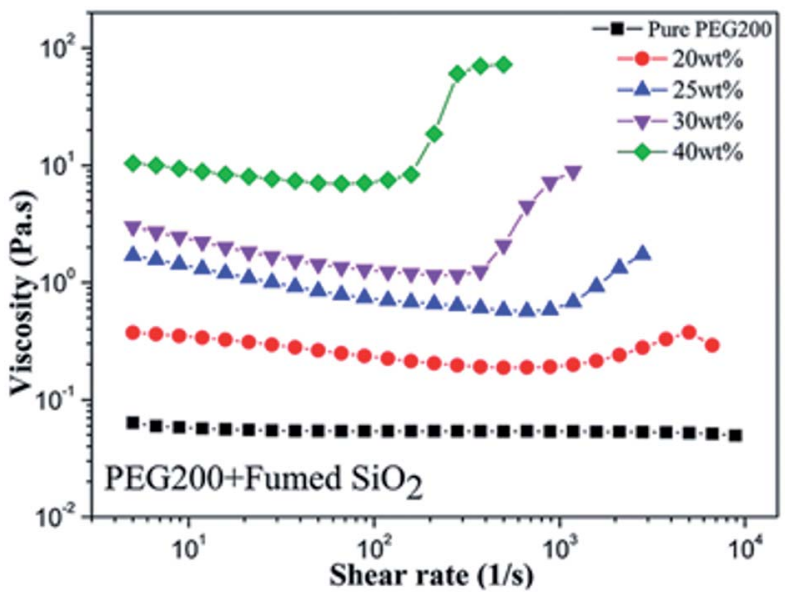

Fig. 13 Shear thickening behaviour with different solid content ${ }^{122}$ (this figure has been reproduced from ref. 122 with permission from The Royal Society of Chemistry).

Another factor which has decisive influence in determining the critical shear rate and peak viscosity of STF is particle size. Barnes $^{125}$ and Lee et al. ${ }^{136}$ showed that as particle size increases the onset of shear thickening moves towards lower shear rate (Fig. 14). This is probably because for a given volume fraction, the number of smaller size particles increases and so is the interaction among these particles.

Particle size distribution also impacts shear thickening behaviour. A wide continuous particle size distribution causes the critical shear rate to rise, while a narrower distribution causes the thickening to occur at lower shear rates. ${ }^{32}$

5.4.3 Particle-particle interaction and particle hardness. Particle-particle interaction is also found to be an important parameter for STF. It is an established realization that shear thickening ceases to occur when at no shear, particles adhere to one another, implying that particles should either be neutral or should constantly repel each other through electrostatic, entropic or steric interactions. Thus, flocculated and deflocculated suspensions show opposite behaviour - thixotropic and rheopectic, respectively. ${ }^{125}$ Particle hardness also has significant effect on shear thickening behaviour. A study conducted by Kalman et al. ${ }^{137}$ on the effect of particle hardness, reported that

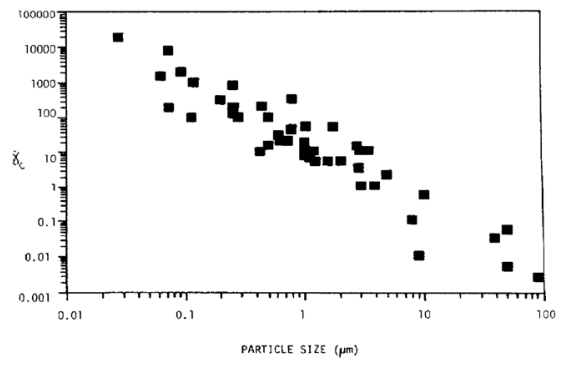

Fig. 14 Effect of particle size on shear thickening behaviour of STF ${ }^{125}$ (this figure has been reproduced from ref. 125 with permission from AIP Publishing).
$\mathrm{SiO}_{2}$ particle systems $\left(\mathrm{SiO}_{2}\right.$ being harder), displayed systematic increase in yarn pull-out, puncture, and ballistic resistance, resulting in better performance than that of softer PMMA (polymethyl methacrylate) particle systems. The authors attempted to explain this behaviour assuming the mobility mechanisms to govern the experiment, in which harder particles are more likely to restrict yarn and filament movement. This is because of the higher potential of harder particles to engage with the filaments, besides being able to bear higher stress levels without deformation.

5.4.4 Temperature. Temperature has a direct influence on viscosity for it agitates the particles, driving them to greater mobility due to increased kinetic and thermal energy. Hence, it is not difficult to understand that viscosity decreases with increasing temperature. This in turn has a negative impact on the shear thickening mechanism. Fig. 15 depicts that the critical shear rate increases while the peak viscosity decreases with the increase in temperature. ${ }^{110,122,139}$ This can be explained in terms of increased repulsive interaction among the particles at high temperatures, requiring much higher external forces to overcome this repulsion for the particles to form hydroclusters.

5.4.5 $\mathrm{pH}$. The role of $\mathrm{pH}$ in influencing the behaviour of STF is very significant. Extensive research has shown that $\mathrm{pH}$ alters the surface charge and changes the inter-particle repulsive or attractive forces. Chen et al. ${ }^{140}$ studied the effect of acidity or basicity of polystyrene-ethylacrylate colloidal dispersion on its thickening behaviour and found out that critical shear rate decreases with decreasing $\mathrm{pH}$ on acid addition, while the opposite was found for alkali added STF samples. A related work by Shan et al. ${ }^{141}$ showed similar results. The authors prepared $20 \%(\mathrm{w} / \mathrm{w})$ STF using fumed silica and used diluted $\mathrm{HCl}$ and $\mathrm{NaOH}$ to control the pH of STF between 2 and 12. From their rheological results (Fig. 16), it becomes clear that critical shear rate increases, and peak viscosity decreases with the increase in $\mathrm{pH}$.

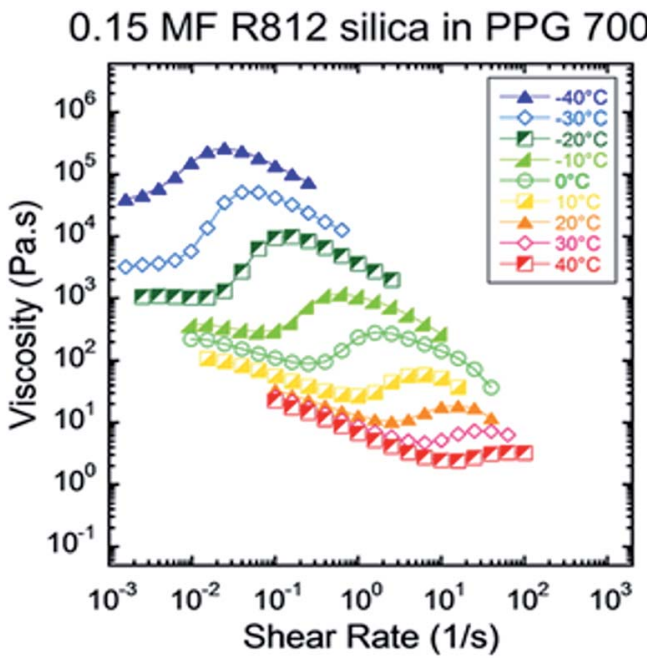

Fig. 15 Effect of temperature on shear thickening behaviour ${ }^{138}$ (this figure has been reproduced from ref. 138 with permission from American Chemical Society). 
5.4.6 Nano fillers. Addition of nanofillers can help to tune the onset of shear thickening so as to suit different requirements. Huang et al. ${ }^{\mathbf{1 4 3}}$ added a very small amount of graphene oxide $(0.1 \%$ to $0.3 \%)$ into a silica/PEG-based STF to modify the shear thickening behaviour. They found that critical shear rate decreases, and the peak viscosity increases with the addition of graphene oxide. Wang et al. ${ }^{\mathbf{1 4 2}}$ and Laha et al. ${ }^{\mathbf{1 4 4}}$ used halloysite nanotube (Hal nanotube or HNT) as nanofillers to alter the shear thickening behaviour and found almost identical results (Fig. 17). The presence of nanofillers facilitates the formation of clusters by the particles as the latter agglomerate around the former. Thus, critical shear rate reduces, and peak viscosity increases. Sha et al. ${ }^{\mathbf{1 4 5}}$ incorporated two carbon nanofillers into Si-PEG STF in the form of nanotubes (CNTs) and graphene nanoplatelets (GNs), in different volume fraction, individually and together, and found that the shear thickening behaviour enhanced in samples with additives because of better aggregation effect. The presence of nanofillers improved the particles interaction and this was observed to be more prominent in CNT-STF than in GN-STF due to the former's specific tubular shape. The combination of both CNTs and GNs showed even better results due to synergistic effects. Quite the contrary, the findings of Hasanzadeh et $a{ }^{\mathbf{1 4 6}}$ and Gürgen et al. ${ }^{89}$ showed opposing results, i.e., the degree of shear thickening reduced with addition of nanofillers. Hasanzadeh et $a l .{ }^{\mathbf{1 4 6}}$ found that addition of carbon MWNTs to silica-PEG STF caused the critical viscosity to reduce and the shear thickening to commence at higher critical shear rate. They argued that the presence of the MWNTs resulted in increased hydrogen bonding with PEG and silica as well, necessitating the use of higher shear rate to overcome this interaction. This led to delayed shear thickening. Gurgen et al., ${ }^{89}$ however, argued that the presence of SiC additives in silica-PEG STF restricted the silica from agglomerating, thereby, preventing shear thickening from occurring, unless higher hydrodynamic forces were applied. Hence, the thickening process was delayed and the thickening ratio, defined as the ratio of maximum viscosity to critical viscosity, was lowered.

\subsection{Effect of STF on failure mechanism of fabrics}

The mechanism of STF-fabric interaction during impact has long been debated. Unfortunately, thorough understanding of

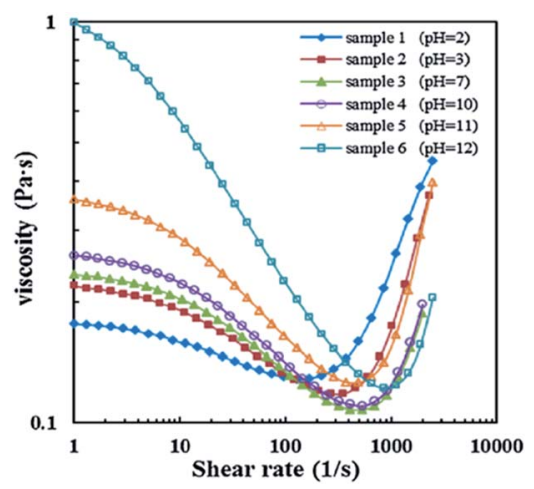

Fig. 16 Effect of $\mathrm{pH}$ on shear thickening behaviour ${ }^{141}$ (this figure has been reproduced from ref. 141 with permission from Elsevier).

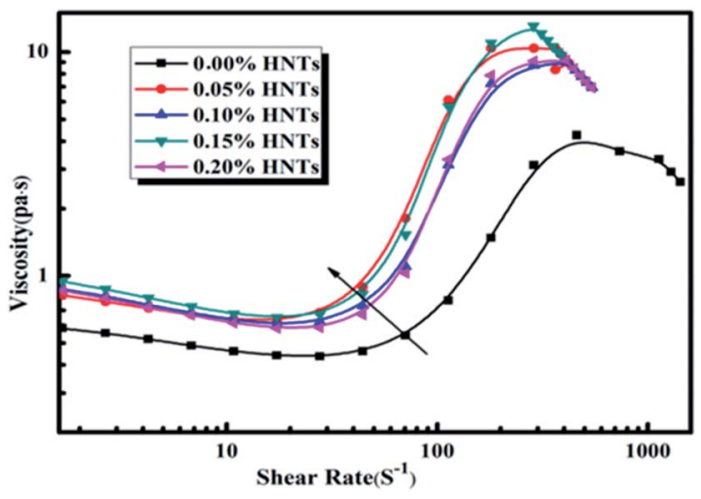

Fig. 17 Effect of Hal nanotube content on shear thickening behaviour $^{142}$ (this figure has been reproduced from ref. 142 with permission from World Scientific Pub.).

the exact role of STF to enhance the impact resistance of highperformance fabrics is still quite obscure. Some researchers argue that increased friction is responsible for enhanced impact performance, ${ }^{32,33,90,147}$ while others believe that the inherent shear thickening phenomenon also plays a vital role in energy absorption. ${ }^{16,82,83,137,148-150}$

In their attempt to understand the STF-fabric interaction mechanism, Majumdar et al. ${ }^{\mathbf{6 8}}$ studied the stage-wise deformation pattern on neat and STF treated fabrics. Three distinct zones were observed in the force/energy plots against time as depicted in Fig. 18. Zone 1 or elastic zone was found to be linear in both untreated and STF treated fabrics, though longer in time in the case of the latter. Zone 2 or slippage/breakage zone was different for untreated and STF treated fabrics. For untreated fabrics, there was a fluctuation of force due to slippage and breakage of yarns which precluded any further increase in force in this zone. On the contrary, STF treated fabrics showed further increase in force in zone 2. The STF treated fabrics showed lesser yarn pull-out and more contribution from secondary yarns in energy absorption during impact. It was also observed that zone 1 and 2 collectively contributed about $40 \%$ of the total energy absorption in untreated fabrics and about $80 \%$ in STF treated fabrics. For untreated fabrics, zone 3 or failure zone was longer as compared to that of STF treated fabrics due to yarn pull-out in case of the former.

A study by Kalman et al. ${ }^{137}$ showed that yarn pull-out is the most prevalent mode of failure for neat and PMMA treated fabrics. However, fibre and yarn rupture are the primary modes of failure and energy absorption for both silica-dry and silicaSTF treated fabrics (Fig. 19).

\subsection{Chemical modification of silica nanoparticles}

Silica particles in nano dimension are very active particles. Thus, it is very difficult to obtain very high weight fraction of silica in STF due to particle aggregation. Surface modifications can be done to improve the dispersion of silica nanoparticles in dispersing medium. For example, the use of silane coupling agents is very common. They have a unique bi-functional structure with one group capable of reacting with silica and 


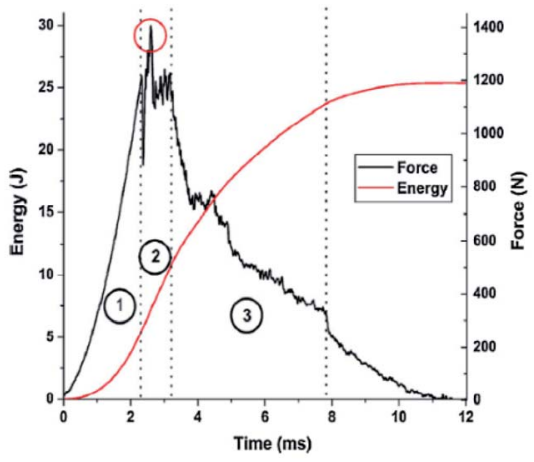

(a)

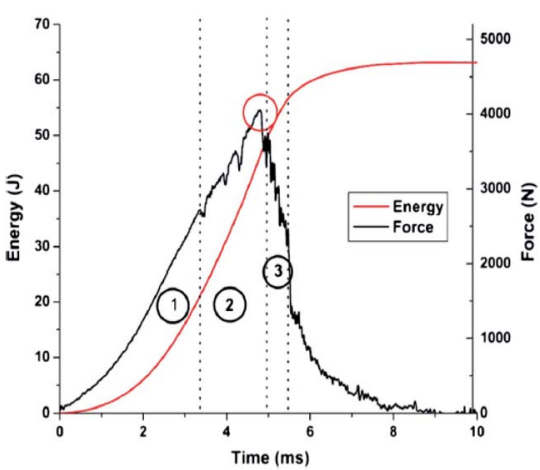

(b)

Fig. 18 Force vs. time and energy vs. time graphs of (a) untreated and (b) STF treated Kevlar fabrics ${ }^{68}$ (this figure has been reproduced from ref. 68 with permission from Elsevier).

the other group compatible with the dispersing medium ${ }^{\mathbf{1 5 1}}$ The bonding between the silane and the silica surface changes the hydrophilic surface into a hydrophobic one. The $\mathrm{Si}-\mathrm{O}-\mathrm{Si}-$ $\mathrm{C}$ moiety formed by this reaction not only provides a chemically stable attachment to the silica matrix, but also allows further modification with high chemical stability. ${ }^{152}$ Radhakrishnan et al. ${ }^{153}$ used polymer grafting technique to modify the surface of the silica nanoparticles (Fig. 20). Yu et al. ${ }^{109}$ used ethylene glycol (EG) as the surface modifying agent for silica (Fig. 21).

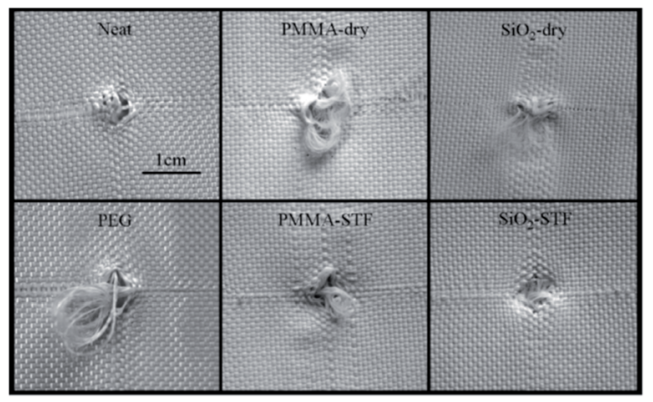

Fig. 19 Failure modes of fabric during impact ${ }^{137}$ (this figure has been reproduced from ref. 137 with permission from American Chemical Society).

\subsection{Use of nanorods of metal oxides}

Surface modification by generating zinc oxide $(\mathrm{ZnO})$ nanorods on high performance fabrics, a technique used to increase interfacial strength, have been explored by various researchers. ${ }^{\mathbf{1 5 6 - 1 6 2}}$ It becomes clear from the works of Galan et al. ${ }^{156}$ Ehlert et al. ${ }^{159}$ Majumdar et al. ${ }^{161}$ and Hwang et al. ${ }^{155,160}$ that $\mathrm{ZnO}$ nanostructures developed on the surface of highperformance fabrics help to improve both the yarn pull-out and impact energy absorption, due to improved inter-yarn friction, without any deterioration in tensile strength. Various methods can be adopted to grow nanostructures on high performance fabrics. However, the most sought after one is the hydrothermal method $^{\mathbf{1 6 3 , 1 6 4}}$ because it is relatively simple and causes minimum damage to the fibre due to low processing temperature. Fig. 22(a) shows the growth of $\mathrm{ZnO}$ nanorods on Kevlar fabric surface whereas Fig. 22(b) presents the SEM images of $\mathrm{ZnO}$ nanorod coated Kevlar fabric.

\subsection{Use of three dimensional (3D) fabrics}

Multiple layers of stitched two dimensional (2D) plain woven fabrics are generally used for body armour applications. The disadvantages of this assembly are the adverse effects of stress concentration at crossover points of yarns in fabrics and poor layer to layer stress transfer. To overcome these problems, three dimensional (3D) woven fabrics may be used as an alternative. ${ }^{\mathbf{1 6 5 - 1 6 7}} 3 \mathrm{D}$ woven fabrics have several advantages over $2 \mathrm{D}$ fabrics like improved mechanical properties in through-thickness direction, better structural integrity and good layer to layer stress transfer. ${ }^{168}$ It is believed by many researchers that the presence of yarns in $Z$ direction in 3D woven fabrics increases the stiffness, strength and compactness of the structure and its composite. ${ }^{167,169}$ Chevalier et al. ${ }^{170}$ concluded that for the same weight per unit area, stacked 2D fabrics absorb more energy than a 3D (warp interlock) fabric owing to higher volume fraction of yarn inside the 2D structures.

Composites made of 3D structures offer several advantages over $2 \mathrm{D}$ laminates as evident by the results of a comparative study between 2D and 3D woven fabrics on compressive strength, post impact flexural strength and damage area after impact. Composites made of 3D woven fabrics are found to be superior, with reduced possibility of delamination and smaller failure zone. ${ }^{171}$ Different variants of 3D woven structures have been reported by different researchers for ballistic applications..$^{55,170,172,173}$ The general definition and classification of 3D woven fabrics have been given in great detail by Boussu et al. ${ }^{\mathbf{1 7 4}}$ and Fig. 23 shows the structural difference as per this classification.

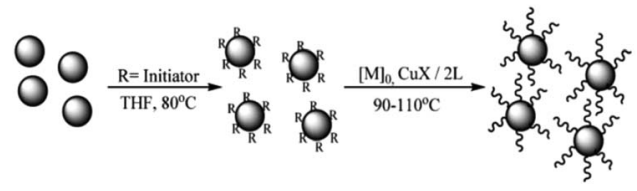

Fig. 20 Surface modification of silica nanoparticles using polymer grafting technique ${ }^{153}$ (this figure has been reproduced from ref. 153 with permission from The Royal Society of Chemistry). 


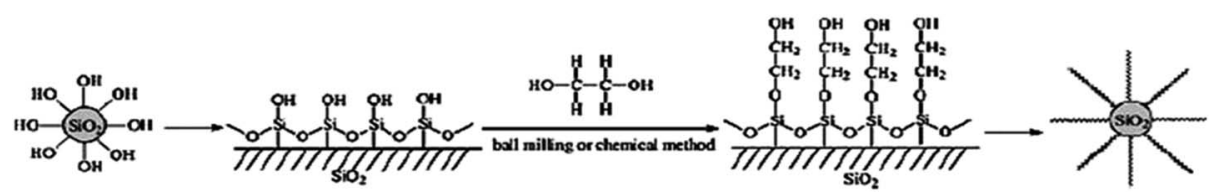

Fig. 21 Reactions of silica nanoparticles with $\mathrm{EG}^{109}$ (this figure has been reproduced from ref. 109 with permission from Springer Nature).

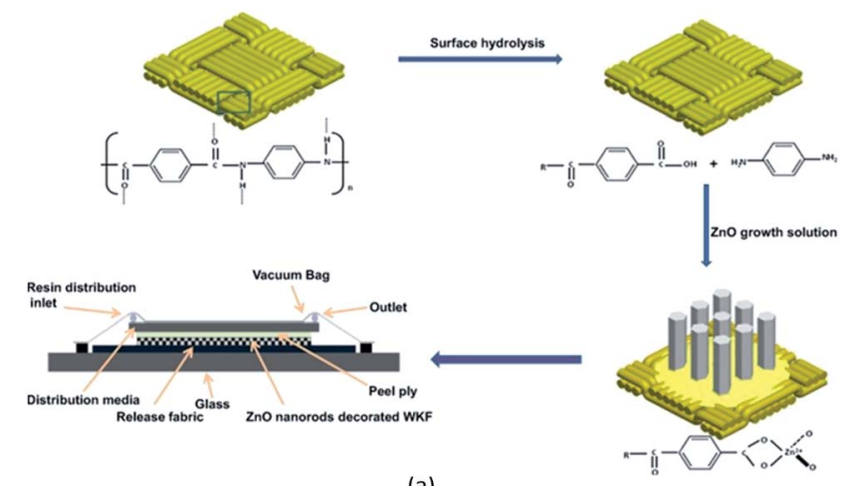

(a)

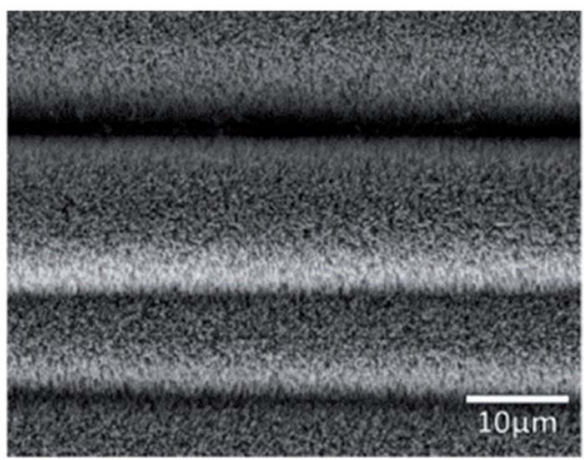

(b)

Fig. 22 (a) ZnO nanorod formation on Kevlar fabric, ${ }^{154}$ (b) ZnO coated fabric $^{155}$ (these figures have been reproduced from ref. 154 and 155 , respectively with permission from Elsevier).

Fig. 24 shows an orthogonal interlock fabric with the three different sets of yarns used in 3D structures, namely binder warp, stuffer warp and weft yarns. As such, structures vary according to the binding depth of the binder warp and angle at which it binds the layers.

5.8.1 Orthogonal interlock structure. In 3D orthogonal fabric, three types of constituent yarns (stuffer, binder and weft) are oriented perpendicularly to each other in longitudinal, vertical and transverse directions, respectively. ${ }^{\mathbf{1 6 8}}$ Mechanical and structural properties of the 3D orthogonal woven fabric and its composites can be varied by changing the weave of binder yarns and number of warp layers. ${ }^{175-179}$ It is important to note that the stuffer yarns absorbe more energy than the binder yarns, probably because of their low crimp. This, therefore, imposes the need to optimise the stuffer to binder ratio to arrive at best performance. Majumdar et $a l .{ }^{\mathbf{1 8 0}}$ found that, in general, the energy absorption capacity of a 3D orthogonal fabric increased with increasing stuffer to binder ratio when subjected to low velocity ballistic impact $\left(165 \pm 10 \mathrm{~m} \mathrm{~s}^{-1}\right)$. Additionally, the double layered STF treated 3D fabrics with stuffer to binder ratio of $4: 1$ was able to stop all bullets from piercing. At higher impact velocity $\left(430 \pm 10 \mathrm{~m} \mathrm{~s}^{-1}\right)$ also, panels containing $3 \mathrm{D}$ fabrics with stuffer to binder ratio of $4: 1$ performed better. Some researchers observed that orthogonal fabrics absorb the more energy when compared to other 3D structures in terms of peak force and total energy. ${ }^{\mathbf{1 8 1 , 1 8 2}}$ This may be because of the absence of crimp, thereby permitting maximum utilisation of yarn properties. Structural stability is another advantage of orthogonal structures. This may stem from the fact that, for the same conditions, a higher fibre volume fraction can be expected for an orthogonal interlock binding than for an angle interlock binding, particularly in the thickness direction. ${ }^{183}$

5.8.2 Angle interlock structure (layer to layer). Generally known as warp interlock fabric, this type of structure also has multiple layers of warp and weft yarns. The binder warp yarn travels from one layer to another layer and then comes back, thus stitching the layers together. ${ }^{\mathbf{1 6 8 , 1 6 9 , 1 7 1}}$

Due to this specific bonding arrangement between layers, 3D warp interlock fabrics are reported to show a small damaged zone, good resistance to delamination and multiple hits when subjected to impact. ${ }^{\mathbf{1 7 9}}$ The stiffness and structural stability increase with the increase in number of layers while the crimp of the wavy yarns varies according to the interlacement pattern. Stuffer warp yarns are generally inserted to increase the structural stability and fibre volume fraction in composites. ${ }^{\mathbf{1 7 0 , 1 7 8 , 1 8 4}}$ The mechanical and structural properties of these $3 \mathrm{D}$ fabrics can be altered by changing the stuffer to binder ratio, number of layers and by changing the binding depth of the binder warps. ${ }^{185}$ Of these, the binding depth has been reported to be one of the major parameters contributing to degradation of tow strength inside the woven structure. ${ }^{\mathbf{1 8 6}}$ Higher values of number of layers and thread density seem to have a positive effect. It has been seen that better impact resistance can be anticipated with balanced or equilibrated structures wherein similar warp and weft densities are employed. ${ }^{179,187}$

5.8.3 Angle interlock structure (through-thickness). Angle interlock structure can also be termed as 'through-thickness' interlock structure, in which, the warp yarns bind the weft yarns by traveling from one surface (top) to other surface (bottom). ${ }^{\mathbf{1 6 8 , 1 6 9 , 1 7 1}}$ This, in general, causes substantial increase in crimp in these warp yarns as compared to that in a warp interlock structure. Like in warp interlock structures, stuffer warp yarns may be added to give structural stability and to increase fibre volume fraction in composites. ${ }^{13,168,171,188}$ These structures have been reported to be least energy absorbent and impact resistant amongst the different $3 \mathrm{D}$ woven fabrics, probably due to lesser interlacements. An 

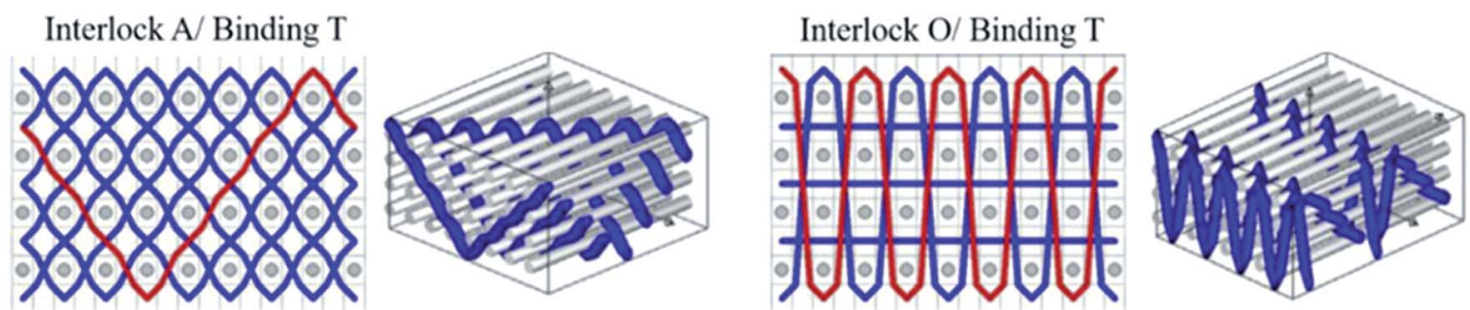

Interlock A/ Binding L
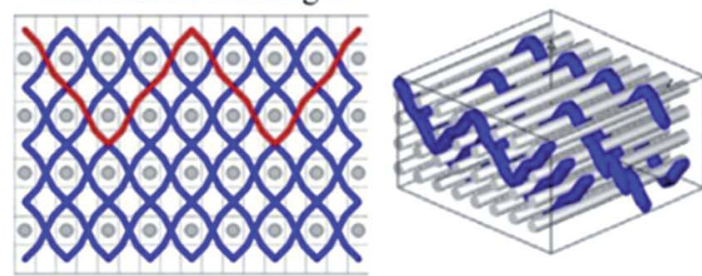

Interlock O/ Binding L

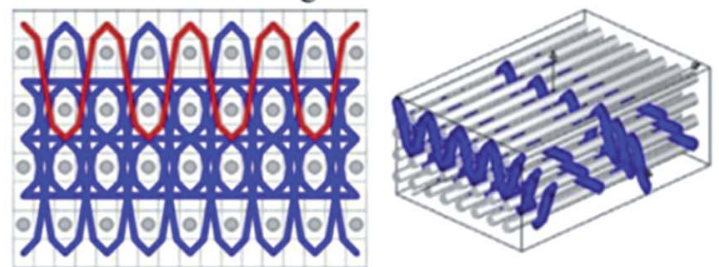

Fig. 23 Classification of 3D woven structures $\left(A=\right.$ angle, $O=$ orthogonal, $L=$ layer to layer, $T=$ through-thickness) ${ }^{174}$ (these figures have been reproduced from ref. 174 with permission from Elsevier).

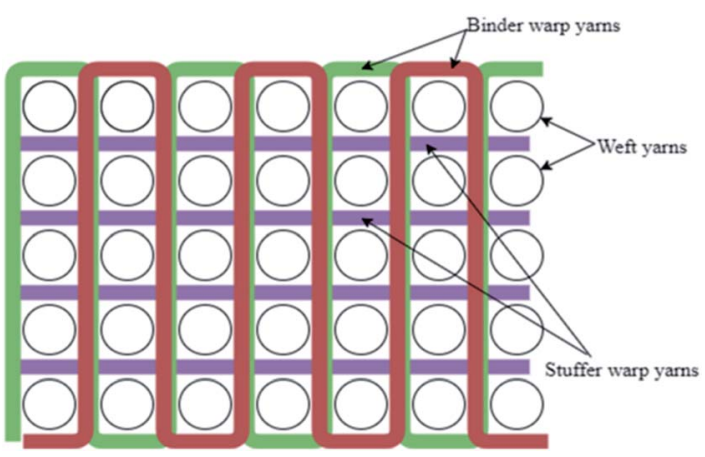

Fig. 24 A 3D orthogonal plain-woven structure showing binder, stuffer and weft yarns.

investigation by Yang et al. ${ }^{189}$ revealed that angle interlock structures show weaker gripping power, in addition to the normal energy absorption mechanisms like $2 \mathrm{D}$ woven fabrics. It has been reported that angle interlock fabrics also offer least resistance to shear, owing to minimal contact points. ${ }^{190}$ This unique property enables near-net dome shapes to be formed readily without the need of cutting, stitching and folding. Hence, moldability is one of the most superior and attractive properties of angle interlock structures as far as 3D woven fabrics are concerned. This property has enabled researchers to develop seamless ballistic vests for female personnel to suit their curvaceous body shape. ${ }^{14}$

\section{Future trends}

The constant need for reduced weight and enhanced performance has marked a shift in the choice of material for ballistic applications. UHMWPE fibres are now being explored more extensively than aramids due to lower density of the former. Hence, in the near future, one might expect UHMWPEs to replace aramids altogether. Another observable trend is the application of multiphase STF with the addition of nanofillers such as carbon nanotubes and graphene instead of a single phase STF. In general, multi-phase STFs show higher peak viscosity, which is a requirement for ballistic resistance. Yet another trend that may take precedence in the coming years is the use of STF treated 3D structures in lieu of the currently used 2D structures. The use of carbon nanotubes in impact and ballistic applications at different stages, i.e., as an additive to the matrix or as a reinforcement to high-performance yarn may be exploited to greater extent as research progresses. ${ }^{191-193}$

\section{Summary}

The present review critically analyses the vast body of research pursued to understand the roles of fibrous materials on ballistic impact resistance behaviour of soft body armour. Fibre and yarn properties are of paramount importance and UHMWPE fibres, due to their low density and very high modulus, seem to surpass aramids. Fabric constructions also play decisive roles as UD, 2D, 3D, triaxial and knitted fabrics behave differently during impact. For impact applications, crimpless UD fabric structures facilitate faster and wider dissipation of stress waves and the former is replacing the woven $2 \mathrm{D}$ fabrics to a great extent. Standards and evaluation techniques have also progressed to keep pace with the stringent requirement of body armour users. The use of shear thickening fluids has shown promising results at least against low velocity impact as well as against stab and puncture. Surface modification by developing nanorods of metal oxides have also shown potential in imparting additional energy absorption capacity to the base fibrous structure. Similarly, judicious selection of 3D woven construction may lead to improved impact energy absorption. Hybridization of different materials and structures for synergistic benefits is yet another approach that has been explored and the results are often very promising. The application of carbon nanotubes is also being explored to develop next generation lightweight body armour. 


\section{Conflicts of interest}

There is no conflict to declare.

\section{Acknowledgements}

The authors are thankful to the Defence Research and Development Organization (DRDO), India and Terminal Ballistics Research Laboratory (TBRL), Chandigarh, India for providing financial assistance for this work through Grant No. DFTM/03/ 3203/M/01/JATC and ST-13/TBR-1298, respectively.

\section{References}

1 I. G. Crouch, Body armour - New materials, new systems, Def. Technol., 2019, 15(3), 241-253, DOI: 10.1016/ j.dt.2019.02.002.

2 U.S. Department of Justice, Ballistic Resistance of Body Armor NIJ Standard-0101.06, 2008.

3 National Institute of Justice, Draft NIJ Standard 0101.07 Ballistic Resistance of Body Armor, 2018.

4 K. Horn, K. Biever, K. Burkman, et al., Lightening Body Armor, Pittsburg, 2012.

5 R. Yadav, M. Naebe, X. Wang and B. Kandasubramanian, Body armour materials: from steel to contemporary biomimetic systems, RSC Adv., 2016, 6(116), 115145115174, DOI: 10.1039/C6RA24016J.

6 B. A. Cheeseman and T. A. Bogetti, Ballistic impact into fabric and compliant composite laminates, Compos. Struct., 2003, 61(1-2), 161-173, DOI: 10.1016/S02638223(03)00029-1.

7 J. R. Vinson and J. A. Zukas, On the ballistic impact of textile body armor, J. Appl. Mech., 1975, 42(2), 263-268, DOI: 10.1115/1.3423564.

8 R. A. Prosser, Penetration of nylon ballistic panels by fragment-simulating projectiles Part II: Mechanism of penetration, Text. Res. J., 1988, 58(3), 161-165.

9 High-Performance Fibres, ed. J. W. S. Hearle, Woodhead Publishing Limited, Cambridge, 1st edn, 2001.

$10 \mathrm{~J}$. Van Dingenen, High performance dyneema fibres in composites, Mater. Des., 1989, 10(2), 101-104, DOI: 10.1016/S0261-3069(89)80021-4.

11 P. M. Cunniff and M. A. Auerbach, High performance "M5" fiber for ballistics/structural composites, 23rd Army Sci Conf., 2002, pp. 1-8.

12 P. Bajaj and Sriram, Ballistic protective clothing: An overview, Indian J. Fibre Text. Res., 1997, 22(4), 274-291.

13 A. Bhatnagar and E. S. Parrish, Bi-directional and multiaxial fabrics and fabric composites, US Pat., 6841492 B2, 2005.

$14 \mathrm{X}$. Chen and D. Yang, Use of 3D angle-interlock woven fabric for seamless female body armor: Part 1: Ballistic evaluation, Text. Res. J., 2010, 80(15), 1581-1588, DOI: $10.1177 / 0040517510363187$.

15 Y. S. Lee, E. D. Wetzel Jr, R. G. Egres and N. J. Wagner, Advanced body armor utilizing shear thickening fluids, in 23rd Army Science Conference, Orlando, FL, December 2-5, 2002, pp. 1-6.

16 N. J. Wagner and E. D. Wetzel, Advanced body armor utilizing shear thickening fluids, US Pat., 7498276 B2, 2009.

17 Y. S. Lee, E. D. Wetzel and N. J. Wagner, The ballistic impact characteristics of Kevlar woven fabrics impregnated with a colloidal shear thickening fluid, J. Mater. Sci., 2003, 38(13), 2825-2833, DOI: 10.1023/A:1024424200221.

18 S. Arora and A. Ghosh, Evolution of soft body armor, in Advanced Textile Engineering Materials, 2018, pp. 499-552, DOI: 10.1002/9781119488101.ch13.

19 R. Nayak, I. Crouch, S. Kanesalingam, et al., Body armor for stab and spike protection, Part 1: Scientific literature review, Text. Res. J., 2018, 88(7), 812-832, DOI: 10.1177/ 0040517517690623.

20 Kevlar® fibers, DuPont, http://www.dupont.co.in/productsand-services/fabrics-fibers-nonwovens/fibers/brands/ kevlar/products/dupont-kevlar-fiber.html.

21 A. Srivastava, A. Majumdar and B. S. Butola, Improving the impact resistance of textile structures by using shear thickening fluids: A review, Crit. Rev. Solid State Mater. Sci., 2012, 37(2), 115-129, DOI: 10.1080/ 10408436.2011.613493.

22 V. P. W. W. Shim, C. T. Lim and K. J. Foo, Dynamic mechanical properties of fabric armour, Int. J. Impact Eng., 2001, 25(1), 1-15, DOI: 10.1016/S0734-743X(00) 00038-5.

23 Bladebuster®, http://bladebuster.ca/our-products/cutresistant-clothing/dyneema-vs-kevla, accessed October 20, 2019.

24 A. R. Gonzales, R. B. Schofield and S. V. Hart, Third Status Report of the Attorney General on Body Armor Safety Initiative Testing and Activities, 2005.

25 P. M. Cunniff, An analysis of the system effects in woven fabrics under ballistic impact, Text. Res. J., 1992, 62(9), 495-509, DOI: 10.1177/004051759206200902.

26 B. Pargalanda and F. Hernandezolivares, An analytical model to predict impact behavior of soft armors, Int. J. Impact Eng., 1995, 16(3), 455-466.

27 B. J. Briscoe and F. Motamedi, The ballistic impact characteristics of aramid fabrics: The influence of interface friction, Wear, 1992, 158(1-2), 229-247, DOI: 10.1016/0043-1648(92)90041-6.

28 S. Bazhenov, Dissipation of energy by bulletproof aramid fabric, J. Mater. Sci., 1997, 32(15), 4167-4173, DOI: 10.1007/BF02806188.

29 Y. Duan, M. Keefe, T. A. Bogetti, B. A. Cheeseman and B. Powers, A numerical investigation of the influence of friction on energy absorption by a high-strength fabric subjected to ballistic impact, Int. J. Impact Eng., 2006, 32(8), 1299-1312, DOI: 10.1016/j.ijimpeng.2004.11.005.

30 X. S. Zeng, V. B. C. Tan and V. P. W. Shim, Modelling interyarn friction in woven fabric armour, Int. J. Numer. Methods Eng., 2006, 66(8), 1309-1330, DOI: 10.1002/nme.1596.

31 B. L. Lee, T. F. Walsh, S. T. Won, H. M. Patts, J. W. Song and A. H. Mayer, Penetration failure mechanisms of armor- 
grade fiber composites under impact, J. Compos. Mater., 2001, 35(18), 1605-1633, DOI: 10.1177/ 002199801772661551.

32 S. Gürgen, M. C. Kushan and W. Li, Shear thickening fluids in protective applications: A review, Prog. Polym. Sci., 2017, 75, 48-72, DOI: 10.1016/j.progpolymsci.2017.07.003.

33 A. Khodadadi, G. H. Liaghat, A. R. Sabet, et al., Experimental and numerical analysis of penetration into Kevlar fabric impregnated with shear thickening fluid, $J$. Thermoplast. Compos. Mater., 2018, 31(3), 392-407, DOI: $10.1177 / 0892705717704485$.

34 A. Gawandi, E. T. Thostenson and J. W. Gilllespie, Tow pullout behavior of polymer-coated Kevlar fabric, J. Mater. Sci., 2011, 46(1), 77-89, DOI: 10.1007/s10853-010-4819-3.

35 K. Bilisik, Properties of yarn pull-out in para-aramid fabric structure and analysis by statistical model, Composites, Part A, 2011, 42(12), 1930-1942, DOI: 10.1016/ j.compositesa.2011.08.018.

36 G. Nilakantan and J. W. Gillespie, Yarn pull-out behavior of plain woven Kevlar fabrics: Effect of yarn sizing, pullout rate, and fabric pre-tension, Compos. Struct., 2013, 101, 215-224, DOI: 10.1016/j.compstruct.2013.02.018.

37 N. Pan, Y. Lin, X. Wang and R. Postle, An oblique fiber bundle test and analysis, Text. Res. J., 2000, 70(8), 671674, DOI: 10.1177/004051750007000803.

38 Y. Rao and R. J. Farris, Modeling and experimental study of the influence of twist on the mechanical properties of highperformance fiber yarns, J. Appl. Polym. Sci., 2000, 77(9), 1938-1949, DOI: $\quad$ 10.1002/1097-4628(20000829) 77:9<1938::aid-app9>3.0.co;2-d.

39 M. V. Hosur, U. K. Vaidya, C. Ulven and S. Jeelani, Performance of stitched/unstitched woven carbon/epoxy composites under high velocity impact loading, Compos. Struct., 2004, 64(3-4), 455-466, DOI: 10.1016/ j.compstruct.2003.09.046.

40 C. K. Chu and Y. L. Chen, Ballistic-proof effects of various woven constructions, Fibres Text. East. Eur., 2010, 6(83), 63-67.

41 X. Miao, G. Jiang and X. Kong, Experimental investigation on the stab resistance of warp knitted fabrics, Fibres Text. East. Eur., 2014, 22(5(107)), 65-70.

42 M. E. Messiry and E. Eltahan, Stab resistance of triaxial woven fabrics for soft body armor, J. Ind. Text., 2016, 45(5), 1062-1082, DOI: 10.1177/1528083714551441.

43 M. Karahan, Comparison of ballistic performance and energy absorption capabilities of woven and unidirectional aramid fabrics, Text. Res. J., 2008, 78(8), 718-730, DOI: 10.1177/0040517508090487.

44 C. C. Lin, C. M. Lin, C. C. Huang, et al., Elucidating the design and impact properties of composite nonwoven fabrics with various filaments in bulletproof vest cushion layer, Text. Res. J., 2009, 79(3), 268-274, DOI: 10.1177/ 0040517507097515.

45 A. Laha and A. Majumdar, Interactive effects of $p$-aramid fabric structure and shear thickening fluid on impact resistance performance of soft armor materials, Mater.
Des., 2016, 89(5), 286-293, DOI: 10.1016/ j.matdes.2015.09.077.

46 A. K. Bandaru, Y. Sachan, S. Ahmad, R. Alagirusamy and $\mathrm{N}$. Bhatnagar, On the mechanical response of $2 \mathrm{D}$ plain woven and 3D angle-interlock fabrics, Composites, Part B, 2017, 118, 135-148, DOI: 10.1016/ j.compositesb.2017.03.011.

47 A. K. Bandaru, V. V. Chavan, S. Ahmad, R. Alagirusamy and N. Bhatnagar, Low velocity impact response of $2 \mathrm{D}$ and $3 \mathrm{D}$ Kevlar/polypropylene composites, Int. J. Impact Eng., 2016, 93, 136-143, DOI: 10.1016/j.ijimpeng.2016.02.016.

48 M. Chitrangad, Hybrid Ballistic Fabric, US Pat., 5187003 A, 1993.

49 C. R. Cork and P. W. Foster, The ballistic performance of narrow fabrics, Int. J. Impact Eng., 2007, 34(3), 495-508, DOI: 10.1016/j.ijimpeng.2005.10.006.

50 S. Sockalingam, S. C. Chowdhury, J. W. Gillespie Jr and M. Keefe, Recent advances in modeling and experiments of Kevlar ballistic fibrils, fibers, yarns and flexible woven textile fabrics - a review, Text. Res. J., 2016, 87(8), 9841010, DOI: 10.1177/0040517516646039.

51 V. B. C. Tan, V. P. W. Shim and X. Zeng, Modelling crimp in woven fabrics subjected to ballistic impact, Int. J. Impact Eng., 2006, 32(1-4), 561-574, DOI: 10.1016/ j.ijimpeng.2005.06.008.

52 V. B. C. Tan, V. P. W. Shim and T. E. Tay, Experimental and numerical study of the response of flexible laminates to impact loading, Int. J. Solids Struct., 2003, 40(23), 62456266, DOI: 10.1016/S0020-7683(03)00413-X.

53 M. Karahan, A. Kuş and R. Eren, An investigation into ballistic performance and energy absorption capabilities of woven aramid fabrics, Int. J. Impact Eng., 2008, 35(6), 499-510, DOI: 10.1016/j.ijimpeng.2007.04.003.

54 A. M. Sadegh and P. V. Cavallaro, Mechanics of energy absorbability in plain-woven fabrics: An analytical approach, J. Eng. Fibers Fabr., 2012, 7(1), 10-25. http:// www.jeffjournal.org/papers/Volume7/7.1.2Sadegh.pdf.

55 W. Shi, H. Hu, B. Sun and B. Gu, Energy absorption of 3D orthogonal woven fabric under ballistic penetration of hemispherical-cylindrical projectile, J. Text. Inst., 2011, 102(10), 875-889, DOI: 10.1080/00405000.2010.525815.

56 M. R. Ahmad, W. Yunus, W. Ahmad, J. Salleh and A. Samsuri, Effect of fabric stitching on ballistic impact resistance of natural rubber coated fabric systems, Mater. Des., 2008, 29, 1353-1358, DOI: 10.1016/ j.matdes.2007.06.007.

57 Y. Wang, X. Chen, R. Young, I. Kinloch and G. Wells, A numerical study of ply orientation on ballistic impact resistance of multi-ply fabric panels, Composites, Part B, 2015, 68, 259-265, DOI: 10.1016/ j.compositesb.2014.08.049.

58 X. Chen, D. Sun, Y. Wang and Y. Zhou, 2D/3D Woven Fabrics for Ballistic Protection, in 4th World Conference on 3D Fabrics and Their Applications, 2012, pp. 1-12.

59 A. Majumdar, B. S. Butola and A. Srivastava, Development of soft composite materials with improved impact resistance using Kevlar fabric and nano-silica based shear 
thickening fluid, Mater. Des., 2014, 54, 295-300, DOI: 10.1016/j.matdes.2013.07.086.

60 Standard B of I, Textiles-Bullet Resistant JacketsPerformance Requirements, 2019.

61 Technical Specifications of Light Weight Bullet Proof Jackets, New Delhi, 2009, https://mha.gov.in/sites/default/ files/BPJacket.pdf.

62 H. L. Gower, D. S. Cronin and A. Plumtree, Ballistic impact response of laminated composite panels, Int. J. Impact Eng., 2008, 35(9), 1000-1008, DOI: 10.1016/ j.ijimpeng.2007.07.007.

63 G. Nilakantan, R. L. Merrill, M. Keefe, J. W. Gillespie and E. D. Wetzel, Experimental investigation of the role of frictional yarn pull-out and windowing on the probabilistic impact response of kevlar fabrics, Composites, Part B, 2015, 68, 215-229, DOI: 10.1016/ j.compositesb.2014.08.033.

64 Military Textiles, ed. E. Wilusz, Woodhead Publishing Limited, Cambridge, 1st edn, 2008.

65 D. J. Carr, Failure mechanisms of yarns subjected to ballistic impact, J. Mater. Sci. Lett., 1999, 18, 585-588, DOI: $10.1023 / \mathrm{a}: 1006655301587$.

66 N. K. Naik and P. Shrirao, Composite structures under ballistic impact, Compos. Struct., 2004, 66(1-4), 579-590, DOI: 10.1016/j.compstruct.2004.05.006.

67 T. G. Montgomery, P. L. Grady and C. Tomasino, The effects of projectile geometry on the performance of ballistic fabrics, Text. Res. J., 1982, 52(7), 442-450, DOI: 10.1177/ 004051758205200703.

68 A. Majumdar, B. S. Butola and A. Srivastava, An analysis of deformation and energy absorption modes of shear thickening fluid treated Kevlar fabrics as soft body armour materials, Mater. Des., 2013, 51, 148-153, DOI: 10.1016/j.matdes.2013.04.016.

69 J. E. Kirkwood, K. M. Kirkwood, Y. S. I. L. Lee, et al., Yarn pull-out as a mechanism for dissipating ballistic iimpact energy in Kevlar KM-2 fabric: Part I: Producing ballistic performance, Text. Res. J., 2004, 74(10), 920-928.

70 J. E. Kirkwood, K. M. Kirkwood, Y. S. Lee, R. G. Egres, N. J. Wagner and E. D. Wetzel, Yarn pull-out as a mechanism for dissipating ballistic impact energy in Kevlar(R) KM-2 fabric: Part II: Predicting ballistic performance, Text. Res. J., 2004, 74(11), 939-948, DOI: 10.1177/004051750407401101.

71 S. A. R. D. Sebastian, A. I. Bailey, B. J. Briscoe and D. Tabor, Effect of a softening agent on yarn pull-out force of a plain weave fabric, Text. Res. J., 1986, 56(10), 604-611.

72 S. A. R. D. Sebastian, A. I. Bailey, B. J. Briscoe and D. Tabor, Extensions, displacements and forces associated with pulling a single yarn from a fabric, J. Phys. D: Appl. Phys., 1987, 20(1), 130-139, DOI: 10.1088/0022-3727/20/1/020.

73 M. Martinez, C. Navarro, R. Cortes, J. Rodriguez and V. Sanchez-Galvez, Friction and wear behaviour of Kevlar fabrics, J. Mater. Sci., 1993, 28, 1305-1311.

74 Z. Dong and C. T. Sun, Testing and modeling of yarn pullout in plain woven Kevlar fabrics, Composites, Part A,
2009, 40(12), 1863-1869, DOI: 10.1016/ j.compositesa.2009.04.019.

$75 \mathrm{~K}$. Bilisik, Experimental determination of yarn pull-out properties of para-aramid (Kevlar@) woven fabric, J. Ind. Text., 2012, 41(3), 201-221, DOI: $10.1177 /$ 1528083711413411.

76 K. Bilisik, Stick-slip behavior of para-aramid (Twaron ${ }^{\circledR}$ ) fabric in yarn pull-out, Text. Res. J., 2013, 83(1), 13-33, DOI: 10.1177/0040517512449052.

77 K. Bilisik and M. Korkmaz, Single and multiple yarn pullouts on aramid woven fabric structures, Text. Res. J., 2011, 81(8), 847-864, DOI: 10.1177/0040517510391703.

78 M. R. Ahmad, W. Y. Wan Ahmad, J. Salleh and A. Samsuri, Performance of Natural Rubber Coated Fabrics under Ballistic Impact, Malaysian Polymer Journal, 2007, 2(1), 3951.

79 R. Roy, A. Laha, N. Awasthi, A. Majumdar and B. S. Butola, Multi layered natural rubber coated woven $p$-aramid and UHMWPE fabric composites for soft body armor application, Polym. Compos., 2017, 39(10), 3636-3644, DOI: $10.1002 / p c .24391$.

80 N. Hassim, M. R. Ahmad, W. Y. W. Ahmad, A. Samsuri and M. H. M. Yahya, Puncture resistance of natural rubber latex unidirectional coated fabrics, J. Ind. Text., 2012, 42(2), 118131, DOI: 10.1177/1528083711429144.

81 A. Majumdar and A. Laha, Effects of fabric construction and shear thickening fluid on yarn pull-out from highperformance fabrics, Text. Res. J., 2016, 86(9), 2056-2066, DOI: $10.1177 / 0040517515619357$.

82 M. Soutrenon and V. Michaud, Impact properties of shear thickening fluid impregnated foams, Smart Mater. Struct., 2014, 23(3), 035022, DOI: 10.1088/0964-1726/23/3/035022.

83 R. G. Egres, M. J. Decker and C. J. Halbach, et al., Stab resistance of shear thickening fluid (STF) - Kevlar composites for body armor applications, in 24th Army Science Conference, 2004, DOI: 10.1142/ 9789812772572_0034.

84 D. Zielinska, B. Delczyk-Olejniczak, L. Wierzbicki, B. Z. E. Wilbik-Ha gas, M. H. Struszczyk and M. Leonowicz, Investigation of the effect of para-aramid fabric impregnation with shear thickening fluid on quasistatic stab resistance, Text. Res. J., 2014, 84(15), 15691577, DOI: 10.1177/0040517514525881.

85 W. Li, D. Xiong, X. Zhao, L. Sun and J. Liu, Dynamic stab resistance of ultra-high molecular weight polyethylene fabric impregnated with shear thickening fluid, Mater. Des., 2016, 102, 162-167, DOI: 10.1016/ j.matdes.2016.04.006.

86 M. J. Decker, C. J. Halbach, C. H. Nam, N. J. Wagner and E. D. Wetzel, Stab resistance of shear thickening fluid (STF)-treated fabrics, Compos. Sci. Technol., 2007, 67, 565578, DOI: 10.1016/j.compscitech.2006.08.007.

87 J. M. Houghton, B. A. Schiffman, D. P. Kalman, E. D. Wetzel and N. J. Wagner, Hypodermic needle puncture of shear thickening fluid (STF)-treated fabrics, in Proceedings of SAMPE, 2007, pp. 1-11, https://sites.udel.edu/ 
wagnergroup/files/2015/03/Houghton_SAMPE07-needleFINAL_pub-2gbvb2l.pdf.

88 H. Mahfuz, F. Clements, V. Rangari, V. Dhanak and G. Beamson, Enhanced stab resistance of armor composites with functionalized silica nanoparticles, $J$. Appl. Phys., 2009, 105(6), DOI: 10.1063/1.3086431.

89 S. Gürgen and M. C. Kus, The stab resistance of fabrics impregnated with shear thickening fluids including various particle size of additives, Composites, Part A, 2017, 94, 50-60, DOI: 10.1016/j.compositesa.2016.12.019.

90 S. Gürgen and M. C. Kuşhan, The effect of silicon carbide additives on the stab resistance of shear thickening fluid treated fabrics, Mech. Adv. Mater. Struct., 2017, 24(16), 1381-1390, DOI: 10.1080/15376494.2016.1231355.

91 J. Gu, X. C. Huang, Y. Li, X. L. Wang, M. W. Shi and Z. Zheng, Improving the stab-resistance performance of ultra high molecular weight polyethylene fabric intercalated with nano-silica-fluid, J. Shanghai Jiaotong Univ., 2014, 19(1), 102-109, DOI: 10.1007/s12204-013-14671.

92 J. Qin, G. Zhang, L. Zhou, J. Li and X. Shi, Dynamic/quasistatic stab-resistance and mechanical properties of soft body armour composites constructed from Kevlar fabrics and shear thickening fluids, RSC Adv., 2017, 7, 3980339813, DOI: 10.1039/c7ra07549a.

93 J. L. Park, B. I. Yoon, J. G. Paik and T. J. Kang, Ballistic performance of $p$-aramid fabrics impregnated with shear thickening fluid; Part I - Effect of laminating sequence, Text. Res. J., 2012, 82(6), 527-541, DOI: 10.1177/ 0040517511420765.

94 J. L. Park, B. I. Yoon, J. G. Paik and T. J. Kang, Ballistic performance of $p$-aramid fabrics impregnated with shear thickening fluid; Part II - Effect of fabric count and shot location, Text. Res. J., 2012, 82(6), 542-557, DOI: 10.1177/ 0040517511420765.

95 A. Majumdar, B. S. Butola and A. Srivastava, Impact performance and energy absorption modes of kevlar fabrics treated with shear thickening fluid, in Fiber Society 2012 Spring Conference: Fiber Research for Tomorrow's Applications, 2012.

96 N. J. Wagner and J. F. Brady, Shear thickening in colloidal dispersions, Phys. Today, 2009, 62(10), 27-32, DOI: 10.1063/1.3248476.

97 L. Sun, D. Xiong and C.-Y. Xu, Application of shear thickening fluid in ultra high molecular weight polyethylene fabric, J. Appl. Polym. Sci., 2013, 129(4), 1922-1928, DOI: 10.1002/app.38844.

98 S. Li, Y. Wang, J. Ding, H. Wu and Y. Fu, Effect of shear thickening fluid on the sound insulation properties of textiles, Text. Res. J., 2014, 84(9), 897-902, DOI: 10.1177/ 0040517513512395.

99 M. Fahool and A. R. Sabet, Parametric study of energy absorption mechanism in Twaron fabric impregnated with a shear thickening fluid, Int. J. Impact Eng., 2016, 90, 61-71, DOI: 10.1016/j.ijimpeng.2015.11.016.

100 R. L. Hoffman, Discontinuous and dilatant viscosity behavior in concentrated suspensions. I. Observation of a flow instability, Trans. Soc. Rheol., 1972, 16(1), 155-173, DOI: 10.1016/0021-9797(74)90059-9.

101 R. L. Hoffman, Explanations for the cause of shear thickening in concentrated colloidal suspensions, $J$. Rheol., 1998, 42, 111-123, DOI: 10.1122/1.550884.

102 R. L. Hoffman, Discontinuous and dilatant viscosity behavior in concentrated suspensions. II. Theory and experimental tests, J. Colloid Interface Sci., 1974, 46(3), 491-506, DOI: 10.1122/1.549250.

103 E. Brown, N. A. Forman, C. S. Orellana, et al., Generality of shear thickening in dense suspensions, Nat. Mater., 2010, 9, 220-224, DOI: 10.1038/nmat2627.

104 J. Qin, G. Zhang and X. Shi, Study of a shear thickening fluid: the suspensions of monodisperse polystyrene microspheres in polyethylene glycol, J. Dispersion Sci. Technol., 2017, 38(7), 935-942, DOI: 10.1080/ 01932691.2016.1216435.

105 Y. Lee, R. Egres and K. M. Kirkwood, The effect of rheological parameters on the ballistic properties of shear thickening fluid (STF) - Kevlar composites, in NUMIFORM, Columbus, 2004, DOI: 10.1063/1.1766538.

106 X. Z. Zhang, W. H. Li and X. L. Gong, The rheology of shear thickening fluid (STF) and the dynamic performance of an STF-filled damper, Smart Mater. Struct., 2008, 17, 035027, DOI: 10.1088/0964-1726/17/3/035027.

107 T. J. Kang, K. H. Hong and M. R. Yoo, Preparation and properties of fumed silica/Kevlar composite fabrics for application of stab resistant material, Fibers Polym., 2010, 11(5), 719-724, DOI: 10.1007/s12221-010-0719-z.

108 T. J. Kang, C. Y. Kim and K. H. Hong, Rheological behavior of concentrated silica suspension and its application to soft armor, J. Appl. Polym. Sci., 2012, 124, 1534-1541, DOI: 10.1002/app.

109 K. Yu, H. Cao, K. Qian, X. Sha and Y. Chen, Shearthickening behavior of modified silica nanoparticles in polyethylene glycol, J. Nanopart. Res., 2012, 14, 747.

$110 \mathrm{M}$. Hasanzadeh and V. Mottaghitalab, The role of shearthickening fluids (STFs) in ballistic and stab-resistance improvement of flexible armor, J. Mater. Eng. Perform., 2014, 23(4), 1182-1196, DOI: 10.1007/s11665-014-0870-6.

111 M. Hasanzadeh, V. Mottaghitalab and M. Rezaei, Rheological and viscoelastic behavior of concentrated colloidal suspensions of silica nanoparticles: A response surface methodology approach, Adv. Powder Technol., 2015, 26(6), 1570-1577, DOI: 10.1016/j.apt.2015.08.011.

112 T. A. Hassan, V. K. Rangari and S. Jeelani, Synthesis, processing and characterization of shear thickening fluid (STF) impregnated fabric composites, Mater. Sci. Eng., A, 2010, 527(12), 2892-2899, DOI: 10.1016/ j.msea.2010.01.018.

113 T. A. Hassan, V. K. Rangari and S. Jeelani, Sonochemical synthesis and rheological properties of shear thickening silica dispersions, Ultrason. Sonochem., 2010, 17(5), 947952, DOI: 10.1016/j.ultsonch.2010.02.001.

114 Y. Park, Y. Kim, A. H. Baluch and C.-G. Kim, Empirical study of the high velocity impact energy absorption characteristics of shear thickening fluid (STF) 
impregnated Kevlar fabric, Int. J. Impact Eng., 2014, 72, 6774, DOI: 10.1016/j.ijimpeng.2014.05.007.

115 J. Ding, P. Tracey, W. Li, G. Peng, P. G. Whitten and G. G. Wallace, Review on shear thickening fluids and applications, Textiles and Light Industrial Science and Technology, 2013, 2(4), 161-173.

116 J. Qin, G. Zhang, X. Shi and M. Tao, Study of a shear thickening fluid: the dispersions of silica nanoparticles in 1-butyl-3-methylimidazolium tetrafluoroborate, J. Nanopart. Res., 2015, 17(8), 333, DOI: 10.1007/s11051-0153144-9.

117 W. H. Boersma, J. Laven and H. N. Stein, Shear thickening (dilatancy) in concentrated dispersions, Am. Inst. Chem. Eng., 1990, 36(3), 321-332, DOI: 10.1002/aic.690360302.

118 A. K. Gurnon and N. J. Wagner, Microstructure and rheology relationships for shear thickening colloidal dispersions, J. Fluid Mech., 2015, 769, 242-276, DOI: 10.1017/jfm.2015.128.

119 R. G. Egres, F. Nettesheim and N. J. Wagner, Rheo-SANS investigation of acicular-precipitated calcium carbonate colloidal suspensions through the shear thickening transition, J. Rheol., 2006, 50(5), 685-709, DOI: 10.1122/ 1.2213245.

120 R. G. Egres and N. J. Wagner, The rheology and microstructure of acicular precipitated calcium carbonate colloidal suspensions through the shear thickening transition, J. Rheol., 2005, 49(3), 719-746, DOI: 10.1122/ 1.1895800 .

121 J. F. Brady and G. Bossis, The rheology of concentrated suspensions of spheres in simple shear flow by numerical simulation, J. Fluid Mech., 1985, 155, 105-129, DOI: 10.1017/S0022112085001732.

122 X.-Q. Liu, R.-Y. Bao, X.-J. Wu, W. Yang, B.-H. Xie and M.-B. Yang, Temperature induced gelation transition of a fumed silica/PEG shear thickening fluid, RSC Adv., 2015, 5(24), 18367-18374, DOI: 10.1039/c4ra16261g.

123 B. J. Maranzano and N. J. Wagner, The effects of interparticle interactions and particle size on reversible shear thickening: Hard-sphere colloidal dispersions, $J$. Rheol., 2001, 45(5), 1205-1222, DOI: 10.1122/1.1392295.

124 G. Bossis and J. F. Brady, The rheology of brownian suspensions, J. Chem. Phys., 1989, 91, 1866-1874, DOI: 10.1063/1.457091.

125 H. A. Barnes, Shear-thickening ("Dilatancy") in suspensions of nonaggregating solid particles dispersed in Newtonian liquids, J. Rheol., 1989, 33, 329-366, DOI: 10.1122/1.550017.

126 W. H. Boersma, J. Laven and H. N. Stein, Computer simulations of shear thickening of concentrated dispersions, J. Rheol., 1995, 39, 841, DOI: 10.1122/1.550621.

127 R. G. Egres Jr, Y. S. Lee and J. E. Kirkwood, et al., "Liquid armor": Protective fabrics utilizing shear thickening fluids, in 4th Int. Conf. on Safety and Protective Fabrics, 2004, pp. 1-8.

128 X. Cheng, J. H. McCoy, J. N. Israelachvili and I. Cohen, Imaging the microscopic structure of shear thinning and thickening colloidal suspensions, Science, 2011, 333(6047), 1276-1279, DOI: 10.1126/science.1207032.

129 Dilatancy (granular material), https:/en.wikipedia.org/ wiki/Dilatancy_(granular_material), accessed March 24, 2018.

130 A. B. Metzner and M. Whitlock, Flow behavior of concentrated (dilatant) suspensions, Trans. Soc. Rheol., 1958, 2(1), 239-254, DOI: 10.1122/1.548831.

131 E. Brown and H. M. Jaeger, The role of dilation and confining stresses in shear thickening of dense suspensions, J. Rheol., 2010, 56(4), 875-923, DOI: 10.1122/ 1.4709423.

132 E. Brown and H. M. Jaeger, Shear thickening in concentrated suspensions: phenomenology, mechanisms and relations to jamming, Rep. Prog. Phys., 2014, 77(4), 123, DOI: $10.1088 / 0034-4885 / 77 / 4 / 046602$.

133 R. Seto, R. Mari, J. F. Morris and M. M. Denn, Discontinuous shear thickening of frictional hard-sphere suspensions, Phys. Rev. Lett., 2013, 111(21), 218301, DOI: 10.1103/PhysRevLett.111.218301.

134 N. Y. C. Lin, B. M. Guy, M. Hermes, et al., Hydrodynamic and contact contributions to continuous shear thickening in colloidal suspensions, Phys. Rev. Lett., 2015, 115(22), 228304, DOI: 10.1103/PhysRevLett.115.228304.

135 E. D. Wetzel, Y. S. Lee, R. G. Egres, K. M. Kirkwood, J. E. Kirkwood and N. J. Wagner, The effect of rheological parameters on the ballistic properties of shear thickening fluid (STF)-Kevlar composites, in AIP Conference Proceedings, 2004, pp. 288-293, DOI: 10.1063/1.1766538.

136 B.-W. Lee, I.-J. Kim and C.-G. Kim, The influence of the particle size of silica on the ballistic performance of fabrics impregnated with silica colloidal suspension, $J$. Compos. Mater., 2009, 43(23), 2679-2698, DOI: 10.1177/ 0021998309345292.

137 D. P. Kalman, R. L. Merrill, N. J. Wagner and E. D. Wetzel, Effect of particle hardness on the penetration behavior of fabrics intercalated with dry particles and concentrated particle-fluid suspensions, ACS Appl. Mater. Interfaces, 2009, 1(11), 2602-2612, DOI: 10.1021/am900516w.

138 J. Warren, S. Offenberger, H. Toghiani, C. U. Pittman, T. E. Lacy and S. Kundu, Effect of temperature on the shear-thickening behavior of fumed silica suspensions, ACS Appl. Mater. Interfaces, 2015, 7(33), 18650-18661, DOI: $10.1021 /$ acsami.5b05094.

139 T. Tian, W. Li, J. Ding, G. Alici and H. Du, Study of the temperature effect of shear thickening fluid, in 2013 IEEE/ASME International Conference on Advanced Intelligent Mechatronics (AIM), Wollongong, Australia, 2013, pp. 833837.

140 Q. Chen, W. Zhu, F. Ye, X. Gong, W. Jiang and S. Xuan, pH effects on shear thickening behaviors of polystyreneethylacrylate colloidal dispersions, Mater. Res. Express, 2014, 1(1), 015303, DOI: 10.1088/2053-1591/1/1/015303.

141 L. Shan, Y. Tian, J. Jiang, X. Zhang and Y. Meng, Effects of $\mathrm{pH}$ on shear thinning and thickening behaviors of fumed silica suspensions, Colloids Surf., A, 2015, 464, 1-7, DOI: 10.1016/j.colsurfa.2014.09.040. 
142 Y. Wang, Y. Zhu and Y. Fu, Preparation and properties of HNT-SiO ${ }_{2}$ compounded shear thickening fluid, Nano brief reports and reviews, 2014, 9(8), 1450100, DOI: 10.1142/ S1793292014501008.

143 W. Huang, Y. Wu, L. Qiu, C. Dong, J. Ding and D. Li, Tuning rheological performance of silica concentrated shear thickening fluid by using graphene oxide, Adv. Condens. Matter Phys., 2015, 2015, 1-5, DOI: 10.1155/2015/734250.

144 A. Laha and A. Majumdar, Shear thickening fluids using silica-halloysite nanotubes to improve the impact resistance of $p$-aramid fabrics, Appl. Clay Sci., 2016, 132133, 468-474, DOI: 10.1016/j.clay.2016.07.017.

$145 \mathrm{X}$. Sha, K. Yu and H. Cao, Shear thickening behavior of nanoparticle suspensions with carbon nanofillers, $J$. Nanopart. Res., 2013, 15(7), 1816, DOI: 10.1007/s11051013-1816-x.

146 M. Hasanzadeh and V. Mottaghitalab, Tuning of the rheological properties of concentrated silica suspensions using carbon nanotubes, Rheol. Acta, 2016, 55(9), 759766, DOI: 10.1007/s00397-016-0950-7.

147 X. Gong, Y. Xu, W. Zhu, S. Xuan, W. Jiang and W. Jiang, Study of the knife stab and puncture-resistant performance for shear thickening fluid enhanced fabric, J. Compos. Mater., 2014, 48(6), 641-657, DOI: 10.1177/ 0021998313476525.

148 A. Srivastava, A. Majumdar and B. S. Butola, Improving the impact resistance performance of Kevlar fabrics using silica based shear thickening fluid, Mater. Sci. Eng., A, 2011, 529(25), 224-229, DOI: 10.1016/j.msea.2011.09.021.

149 V. B. C. Tan, T. E. Tay and W. K. Teo, Strengthening fabric armour with silica colloidal suspensions, Int. J. Solids Struct., 2005, 42(5-6), 1561-1576, DOI: 10.1016/ j.ijsolstr.2004.08.013.

150 U. Mawkhlieng and A. Majumdar, Deconstructing the role of shear thickening fluid in enhancing the impact resistance of high-performance fabrics, Composites, Part B, 2019, 175, 107167, DOI: 10.1016/ j.compositesb.2019.107167.

151 Y. Sun, Z. Zhang and C. P. Wong, Study on mono-dispersed nano-size silica by surface modification for underfill applications, J. Colloid Interface Sci., 2005, 292, 436-444, DOI: $10.1016 /$ j.jcis.2005.05.067.

152 S. Ghosh, S. K. Goswami and L. J. Mathias, Surface modification of nano-silica with amides and imides for use in polyester nanocomposites, J. Mater. Chem. A, 2013, 1(19), 6073-6080, DOI: 10.1039/c3ta10381a.

153 B. Radhakrishnan, R. Ranjan and W. J. Brittain, Surface initiated polymerizations from silica nanoparticles, Soft Matter, 2006, 2, 386-396, DOI: 10.1039/b516508c.

154 A. Hazarika, B. K. Deka, D. Y. Kim, K. Kong, Y. B. Park and H. W. Park, Growth of aligned ZnO nanorods on woven Kevlar® fiber and its performance in woven Kevlar® fiber/ polyester composites, Composites, Part A, 2015, 78, 284293, DOI: 10.1016/j.compositesa.2015.08.022.

155 H. S. Hwang, M. H. Malakooti, B. A. Patterson and H. A. Sodano, Increased interyarn friction through $\mathrm{ZnO}$ nanowire arrays grown on aramid fabric, Compos. Sci.
Technol., 2015, 107, 75-81, DOI: 10.1016/ j.compscitech.2014.12.001.

156 U. Galan, Y. Lin, G. J. Ehlert and H. A. Sodano, Effect of ZnO nanowire morphology on the interfacial strength of nanowire coated carbon fibers, Compos. Sci. Technol., 2011, 71(7), 946-954, DOI: 10.1016/ j.compscitech.2011.02.010.

157 Y. Lin, G. Ehlert and H. A. Sodano, Increased interface strength in carbon fiber composites through a $\mathrm{ZnO}$ nanowire interphase, Adv. Funct. Mater., 2009, 19(16), 2654-2660, DOI: 10.1002/adfm.200900011.

158 G. J. Ehlert, U. Galan and H. A. Sodano, Role of surface chemistry in adhesion between $\mathrm{ZnO}$ nanowires and carbon fibers in hybrid composites, ACS Appl. Mater. Interfaces, 2013, 5(3), 635-645, DOI: 10.1021/am302060v.

159 G. J. Ehlert and H. A. Sodano, Zinc oxide nanowire interphase for enhanced interfacial strength in lightweight polymer fiber composites, ACS Appl. Mater. Interfaces, 2009, 1(8), 1827-1833, DOI: 10.1021/am900376t.

160 H. S. Hwang, B. A. Patterson, M. H. Malakooti and H. A. Sodano, Modification of pullout behavior of Kevlar fabric by zinc oxide nanowire reinforcement, ASME 2013 Int Mech Eng Congr Expo IMECE2013, 2013, pp. 1-6.

161 A. Majumdar, B. S. Butola, N. Awasthi, I. Chauhan and P. Hatua, Improving the mechanical properties of $p$ aramid fabrics and composites by developing $\mathrm{ZnO}$ nanostructures, Polym. Compos., 2018, 39(9), 3300-3306, DOI: $10.1002 /$ pc.24346.

162 P. Dixit, A. Ghosh and A. Majumdar, Hybrid approach for augmenting the impact resistance of $p$-aramid fabrics: grafting of $\mathrm{ZnO}$ nanorods and impregnation of shear thickening fluid, J. Mater. Sci., 2019, 54(20), 13106-13117, DOI: 10.1007/s10853-019-03830-z.

163 S. H. Lee, T. Minegishi, J. S. Park, et al., Ordered arrays of ZnO nanorods grown on periodically polarity-inverted surfaces, Nano Lett., 2008, 8(8), 2419-2422, DOI: 10.1021/ nl801344s.

164 R. S. Sabry and O. AbdulAzeez, Hydrothermal growth of $\mathrm{ZnO}$ nano rods without catalysts in a single step, Manuf. Lett., 2014, 2(2), 69-73, DOI: 10.1016/j.mfglet.2014.02.001.

165 N. Khokar, 3D-Weaving: Theory and practice, J. Text. Inst., 2001, 92(2), 193-207, DOI: 10.1080/00405000108659570.

166 B. K. Behera and R. Mishra, 3-Dimensional weaving, Indian J. Fibre Text. Res., 2008, 33(3), 274-287.

167 R. Ghosh and S. De, Z-fiber influence on high speed penetration of $3 \mathrm{D}$ orthogonal woven fiber composites, Mech. Mater., 2014, 68, 147-163, DOI: 10.1016/ j.mechmat.2013.06.008.

168 M. P. Rao, B. V. Sankar and G. Subhash, Effect of Z-yarns on the stiffness and strength of three-dimensional woven composites, Composites, Part B, 2009, 40, 540-551, DOI: 10.1016/j.compositesb.2009.01.011.

169 M. Ansar, W. Xinwei and Z. Chouwei, Modeling strategies of 3D woven composites: A review, Compos. Struct., 2011, 93(8), 1947-1963, DOI: 10.1016/j.compstruct.2011.03.010.

170 C. Chevalier, F. Boussu and J. Nussbaum, 3D warp interlock fabric as an efficient flexible solution for impact protection, 
in, LWAG 2012 Lugano Workshop, Opportunities and Challenges of Light-Weight Armour-Failure Mechanisms, Materials, Experiments and Modeling, At Lugano, Switzerland, 2012.

$171 \mathrm{~J} . \mathrm{Hu}, 3-D$ Fibrous Assemblies: Properties, Applications and Modelling of Three-Dimensional Textile Structures, Woodhead Publishing Limited, Cambridge, 1st edn, 2008.

172 F. Boussu, B. Provost, D. Coutelier, D. Vallee and F. Rondot, New 3D textile composite hybrid solutions against high velocity impact, in International SAMPE Technical Conference, 2012.

173 Y. Mahadik and S. R. Hallett, The effect of compaction on the compressive properties of a 3D woven interlock fabric, in Proceedings of the 10th International Conference on Textile Composites - TEXCOMP 10: Recent Advances in Textile Composites, 2010.

174 F. Boussu, I. Cristian and S. Nauman, General definition of 3D warp interlock fabric architecture, Composites, Part B, 2015, 81, 171-188, DOI: 10.1016/ j.compositesb.2015.07.013.

$175 \mathrm{X}$. Wang, B. Hu, Y. Feng, et al., Low velocity impact properties of 3D woven basalt/aramid hybrid composites, Compos. Sci. Technol., 2008, 68, 444-450, DOI: 10.1016/ j.compscitech.2007.06.016.

176 Y. Yu, X. Wang, Y. Li and Z. Wang, Numerical simulation of 3D orthogonal woven composite impacted by a spherical bullet, Chin. J. Comput. Phys., 2009, 879-886.

177 Y. Mahadik and S. R. Hallett, Effect of fabric compaction and yarn waviness on 3D woven composite compressive properties, Composites, Part A, 2011, 42(11), 1592-1600, DOI: 10.1016/j.compositesa.2011.07.006.

178 C. Dufour, P. Wang, F. Boussu and D. Soulat, Experimental investigation about stamping behaviour of 3D warp interlock composite preforms, Appl. Compos. Mater., 2014, 21(5), 725-738, DOI: 10.1007/s10443-013-9369-9.

179 B. Provost, F. Boussu, D. Coutellier, D. Vallee, F. Rondot and J. Nussbaum, Armouring solutions against highvelocity impact using 2D laminates and 3D warp interlock composites, J. Ind. Text., 2014, 43(4), 606-626, DOI: 10.1177/1528083713498914.

180 A. Majumdar, A. Laha, D. Bhattacharjee and I. Biswas, Tuning the structure of $3 \mathrm{D}$ woven aramid fabrics reinforced with shear thickening fluid for developing soft body armour, Compos. Struct., 2017, 178, 415-425, DOI: 10.1016/j.compstruct.2017.07.018.

181 R. Mishra, V. Baheti, B. K. Behera and J. Militky, Novelties of 3-D woven composites and nanocomposites, J. Text. Inst., 2014, 105(1), 84-92, DOI: 10.1080/00405000.2013.812266.
182 B. K. Behera and B. P. Dash, Mechanical behavior of 3D woven composites, J. Mater., 2015, 67, 261-271, DOI: 10.1016/j.matdes.2014.11.020.

183 H. L. Yi and X. Ding, Conventional approach on manufacturing 3D woven preforms used for composites, J. Ind. Text., 2004, 34(1), 39-50, DOI: 10.1177/ 1528083704045847.

184 C. Ha-Minh, F. Boussu, T. Kanit, D. Crépin and A. Imad, Effect of frictions on the ballistic performance of a $3 \mathrm{D}$ warp interlock fabric: Numerical analysis, Appl. Compos. Mater., 2012, 19(3-4), 333-347, DOI: 10.1007/s10443-0119202-2.

185 C. Ha-Minh, A. Imad, F. Boussu and T. Kanit, Experimental and numerical investigation of a 3D woven fabric subjected to a ballistic impact, Int. J. Impact Eng., 2016, 88, 91-101, DOI: 10.1016/j.ijimpeng.2015.08.011.

186 F. Boussu, I. Cristian, S. Nauman, P. Lapeyronnie, C. Binetruy and $\mathrm{X}$. Legrand, Effect of 3D-weave architecture on strength transfer from tow to textile composite, in 2nd World Conference on $3 D$ Fabrics and Their Applications, 2009, pp. 2-8.

187 C. Chevalier, J. Nussbaum, D. Coutellier and F. Boussu, Experimental study on the influence of weaving parameters on the ballistic performances of $3 \mathrm{D}$ fabrics, in International Symposium on Ballistics, 2013.

188 K. Luan, B. Sun and B. Gu, Ballistic impact damages of 3-D angle-interlock woven composites based on high strain rate constitutive equation of fiber tows, Int. J. Impact Eng., 2013, 57, 145-158, DOI: 10.1016/j.ijimpeng.2013.02.003.

189 D. Yang, X. Chen, D. Sun, et al., Ballistic performance of angle-interlock woven fabrics, J. Text. Inst., 2016, 108(4), 586-596, DOI: 10.1080/00405000.2016.1176622.

190 X. Chen, W. Lo and A. E. Tayyar, Mouldability of angleinterlock woven fabrics for technical applications, Text. Res. J., 2002, 72(3), 195-200.

191 Y. R. Mahajan, Carbon nanotubes and the pursuit of the ultimate body armor, 2006, https:/www.nanowerk.com/ spotlight/spotid=17548.php, accessed February 19, 2019.

192 S. Sharma, S. R. Dhakate, A. Majumdar and B. P. Singh, Improved static and dynamic mechanical properties of multiscale bucky paper interleaved Kevlar fiber composites, Carbon, 2019, 152, 631-642, DOI: 10.1016/ j.carbon.2019.06.055.

193 Nanocomp Technologies, Inc, http://www.miralon.com/, accessed February 19, 2019. 